\title{
Guide for Environmentally Sustainable Investment Analysis Based on ASTM E3200
}

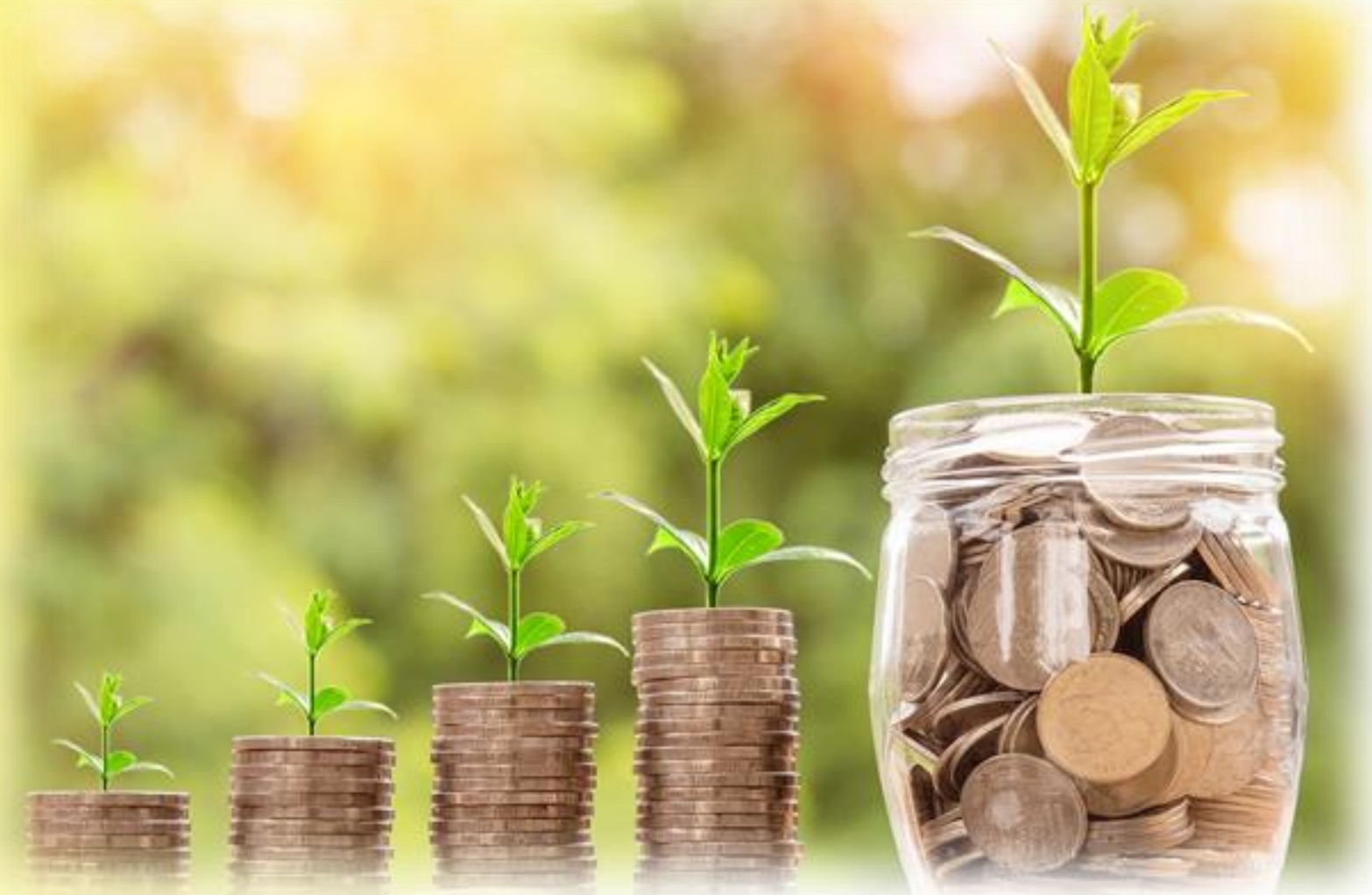

A method for investment analysis that incorporates environmental impact with a focus on manufacturing

Douglas Thomas Anand Kandaswamy

David Butry

This publication is available free of charge from: https://doi.org/10.6028/NIST.AMS.200-11

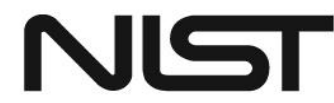

National Institute of Standards and Technology 
NIST Advanced Manufacturing Series 200-11

\title{
Guide for Environmentally Sustainable Investment Analysis Based on ASTM E3200
}

\author{
Douglas Thomas \\ Anand Kandaswamy \\ David Butry \\ Applied Economics Office \\ Engineering Laboratory
}

This publication is available free of charge from:

https://doi.org/10.6028/NIST.AMS.200-11

March 2021

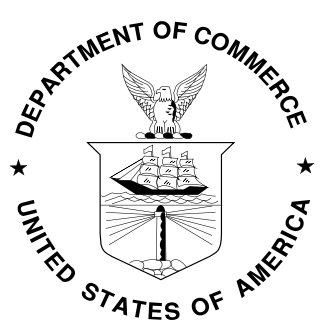

U.S. Department of Commerce Gina M. Raimondo, Secretary

National Institute of Standards and Technology James K. Olthoff, Performing the Non-Exclusive Functions and Duties of the Under Secretary of Commerce for Standards and Technology \& Director, National Institute of Standards and Technology 
Certain commercialentities, equipment, or materials may be identified in this document in order to describe an experimental procedure or concept a dequately. Such identification is not intended to imply recommendation or endorsement by the NationalInstitute of Standards and Technology, nor is it intended to imply that the entities, materials, or equipment a re necessarily the best a vailable for the purpose.

National Institute of Standards and Technology Advanced Manufacturing Series 200-11

Natl. Inst. Stand. Technol. Adv. Man. Ser. 200-11, 47 pages (March 2021)

This publication is available free of charge from: https://doi.org/10.6028/NIST.AMS.200-11 


\begin{abstract}
This guide presents techniques for evaluating manufacturing investments from the perspective of environmentally sustainable manufacturing by pairing economic methods of investment analysis with environmental aspect of manufacturing, including manufacturing processes. The methods are based on ASTM E3200 and, although the focus is on manufacturing, they can be applied under other circumstances (e.g., construction industry investments, agriculture, or mining). The economic techniques include net present value, internal rate of return, payback period, and hurdle rate. The guide also includes sensitivity analyses with a focus on Monte Carlo techniques. The methods presented can be used by manufacturers, regardless of size or complexity, to make environmentally sustainable decisions, including but not limited to whether to embark on an investment, discontinue a manufacturing line, and invest or re-invest in a new project or factory.
\end{abstract}

\title{
Key words
}

Investment analysis; manufacturing; environmental sustainability 


\section{Table of Contents}

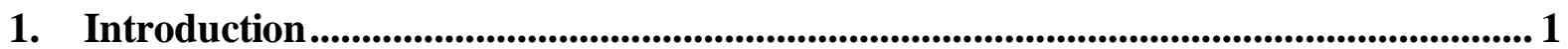

2. Sustainable Investment Analysis ..................................................................................... 3

Step 1.1 - Initial Assessment: Identify Economic Method and ApplyError! Bookmark not defined.

Step 1.2 - Initial Assessment: Conduct Environmental Assessment.. Error! Bookmark not defined.

Step 2 - Consolidate Assessments: Evaluate whether there is a Tradeoff ........................ 6

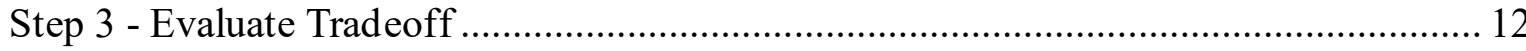

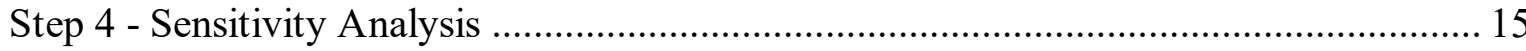

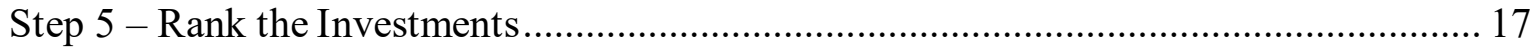

References...................................................................................................................................... 18

Appendix A: Economic Methods ...................................................................................................... 20

Appendix B: Examples ............................................................................................................... 29

\section{List of Tables}

Guide

Table 2.1: Examples of Decision Types ............................................................... 5

Table 2.2: Appropriate Application of Financial Economic Methods ........................... 5

Table 2.3: Consolidating Assessments: Combinations of Outcomes ....Error! Bookmark not defined.

Table 2.4: Sensitivity Analysis Example .................................................................... 17

Appendix A

Table A-1: Example Cash Inflows and Outflows by Year for NPV Calculations .......... 21

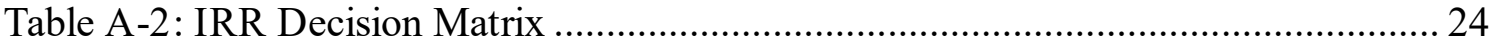

Table A-3: Example Cash Inflows and Outflows by Year for NPV Calculations ......... 24

Appendix B

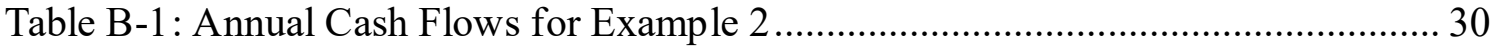

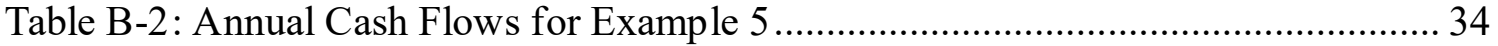

Table B-3: Annual Cash Flows for Example 6 ........................................................ 35

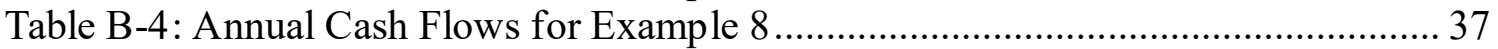

Table B-5: Environmental and Economic Assessment ................................................. 40

Table B-6: Pairwise Comparisons .............................................................................. 40

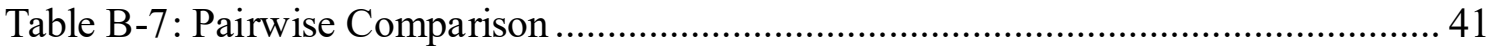

\section{List of Figures}

Guide

Figure 2.1: Five Steps for Environmentally Sustainable Investment Analysis ................ 4

Figure 2.2: Decision Tree for Accept/Reject Decisions ................................................. 8 
Figure 2.3: Decision Tree where Environmental Analysis is Accept/Reject Decision and Economic Analysis is Priority/Ranking Decision ................................................... 9

Figure 2.4: Decision Tree where Economic Analysis is Accept/Reject Decision and Environmental Analysis is Priority/Ranking Decision ............................................... 9

Figure 2.5: Decision Tree for Design, Size, and Ranking/Priority Decisions, One Alternative 10

Figure 2.6: Decision Tree for Design, Size, and Ranking/Priority Decisions, Multiple

Alternatives 11

Figure 2.7: Illu stration of Pairwise Comparison ...................................................... 12 Appendix A

Figure A-1: Example of Net Cash Flows by Year. Appendix B

Figure B-1: Decision Tree for Example 3 .................................................................. 32

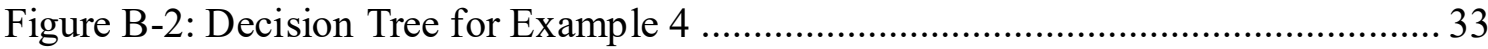

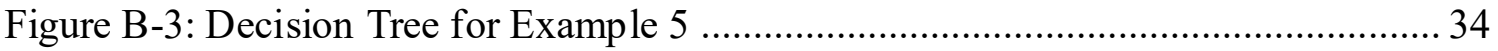

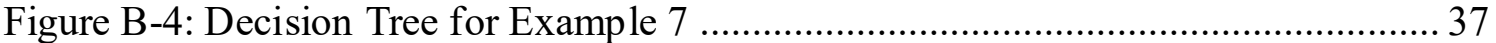

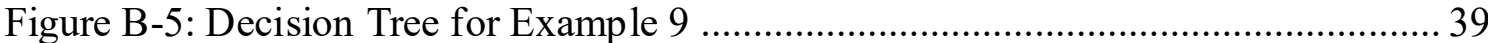




\section{Introduction}

This guide presents techniques for evaluating manufacturing investments from the perspective of environmentally sustainable manufacturing by pairing economic methods of investment analysis with environmental aspect of manufacturing, including manufacturing processes. Although the focus is on manufacturing, the methods can be applied under other circumstances (e.g., construction industry investments, agriculture, or mining). The methods presented are based on ASTM E3200.

The economic techniques discussed include net present value, internal rate of return, payback period, and hurdle rate. These four techniques are deterministic, meaning that they deal with known values that are certain. Probabilistic considerations play no role in determining how these four techniques are deployed. The guide will also move beyond standard deterministic techniques to look at probabilistic methods like the concept of sensitivity analyses, with a focus on Monte Carlo analyses.

The techniques can be used by manufacturers, regardless of size or complexity, to make environmentally sustainable decisions, including but not limited to whether to embark on an investment, discontinue a manufacturing line, and invest or re-invest in a new project or factory. To outline all possible decision types would constitute another guide.

This guide does not assume specific knowledge of financial techniques on the part of the user, besides some knowledge of discounting. The interested reader is encouraged to follow up and consult outside readings to cover financial techniques beyond the scope of this guide. The guide also uses US dollars, percent change in environmental aspects of manufacturing, and unit change in environmental aspects of manufacturing as its primary units.

Techniques for evaluating manufacturing investments from the perspective of environmentally sustainable manufacturing are presented in this guide. It pairs economic methods of investment analysis with environmental aspects of manufacturing. The method presented includes five steps:

1. Initial assessment

2. Consolidate assessments

3. Evaluate tradeoff

4. Sensitivity analysis

5. Rank the investments

There are four types of investment decisions for which four methods of financial economic analysis are applied along with metrics (indicators) for environmental aspects of manufacturing. Methods apply to specific decision types. When combined, financial economic analysis and metrics for environmental aspects of manufacturing result in a combination of financial and environmental outcomes, each associated with an additional procedure. 
This guide provides a method for evaluating investments in terms of their financial merits and environmental merits. This guide can be used to answer whether an investment is both economical and environmentally sustainable or if there is a tradeoff between the environmental aspects of manufacturing and profitability. A tradeoff means there is not a clear best solution and user discretion is required. If there are tradeoffs, this guide provides methods for framing those tradeoff decisions.

The financial merits for this guide are, typically, from the individual stakeholder perspective (e.g., owners and/or investors) or from the perspective of a selection of stakeholders. It is up to the user to decide what financial changes are relevant to them. For instance, if there is a financial cost borne by a third party, the user may opt to exclude it from their analysis, as it is not relevant for them. The environmental merits are from a multi-stakeholder perspective (e.g., societal level) and should follow established standards for evaluating environmental aspects of manufacturing. That is, environmental aspects of manufacturing should not be excluded simply because they do not affect the user. 


\section{Sustainable Investment Analysis}

As seen in Figure 2.1, the method presented includes an iterative process incorporated into a five-step procedure. The first step requires an economic and environmental assessment. The economic assessment evaluates the financial merits of an investment while the environmental assessment evaluates the environmental aspects of manufacturing resulting from the investment. Both assessments evaluate potential investments relative to the status quo (i.e., base case).

Step 2 (Consolidate Assessments) and Step 3 (Evaluate Trad eoff) bring these assessments together for comparison and consider any tradeoffs. The outcome of the economic and environmental assessment results in any one of several outcome combinations (e.g., a financially economical investment that is not environmentally favorable), each having its own implications. Depending on the outcomes, the first three steps may need to be repeated. Step 4 (Sensitivity Analysis) evaluates the impact of uncertainty in the data. There are often variables that are not known with certainty and there is a need to consider the possibility of having different values, resulting in different outcomes. The final step, Step 5, is to rank the investments. A few terms are used in discussing the method, including the following:

- Evaluation: The execution of the complete method discussed in this guide, including Steps 1 through 5 and the repeating of any steps, that results in ranking the status quo and potential investments.

- Iteration: An instance of applying steps 1 through 3

- Comparison or Pairwise Comparison: Where an investment is compared to one other investment using steps 1 through 3.

- Assessment: Applying either economic or environmental methods to determine whether each investment is financially economical, environmentally favorable, accepted, or rejected depending on the decision type.

Multiple economic and environmental assessments are completed and compared. The relation of each economic/environmental assessment is based on the change that results from a particular investment from a comparison case. For an economic assessment, it is the change in finances that result in the investment. For an environmental assessment, it is the change in the environmental aspects of manufacturing that results from the investment.

\section{Step 1.1 - Initial Assessment: Identify Economic Method and Apply}

The first part of Step 1 (i.e., Step 1.1) is an economic analysis. There are four types of economic decisions: accept/reject, design, size, and priority/ranking. An accept/reject decision does not compare investments, but rather determines whether an investment meets a threshold level of performance. A design decision pertains to choices between variations of an investment where only one can be selected. A sizing decision is one that involves different magnitudes within an investment, where only one magnitude can be 


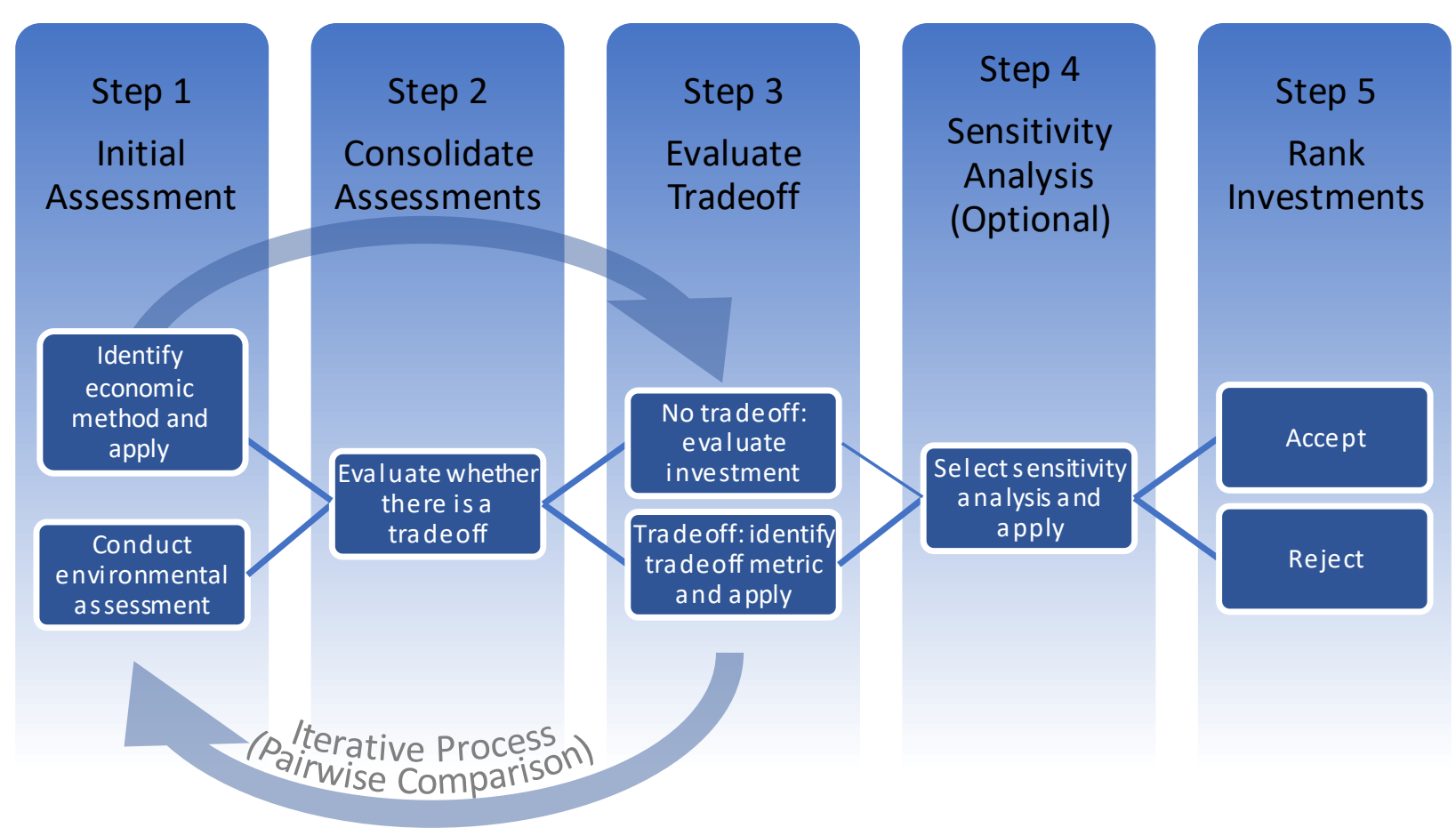

Figure 2.1: Five Steps for Environmentally Sustainable Investment Analysis

selected. A ranking decision includes prioritizing and then selecting one or more investments from a group when a budget is not enough to fund all cost-effective investments. Examples for each of the decision types are presented in Table 2.1.

Four basic approaches for financial economic analysis are discussed in this guide: net present value, internal rate of return, hurdle rate, and payback period. Different approaches are appropriate for each of the four decision types, as defined in Table 2.2. Net present value is appropriate for three of the decision types: accept/reject, design, and size. Internal rate of return is appropriate for all four decision types, while hurdle rate and payback period are only appropriate for accept/reject decisions. Appendix A details each of the methods for financial economic analysis.

\section{Step 1.2 - Initial Assessment: Conduct Environmental Assessment}

Step 1.2 is to examine the environmental aspects of manufacturing of the proposed investments. This guide is not intended to contradict or circumvent the provisions of ISO 14025, ISO 14040, ISO 14044, ISO 14067, ISO14049, or ISO 21930 and encourages their use, and, if the assessment is of a building, ASTM E2921. For the purpose of the method presented here, the user can either use a percent change in environmental aspects of manufacturing or a unit change (e.g., tons of carbon dioxide emitted). These environmental impacts could be measured using methods presented in E3096. 
Table 2.1: Examples of Decision Types

\begin{tabular}{|c|c|}
\hline Accept/Reject & $\begin{array}{l}\text { - Is an additive manufacturing system cost effective? } \\
\text { - Is a new climate control system cost effective? } \\
\text { - Is a new robotic system cost effective? }\end{array}$ \\
\hline Design & $\begin{array}{l}\text { - What robotic system is the most cost effective? } \\
\text { - What HVAC control system is the most cost effective? } \\
\text { - Which milling machine is the most cost effective? } \\
\text { - Is it more cost effective to use steel or aluminum materials? }\end{array}$ \\
\hline Size & $\begin{array}{l}\text { - How many machine tools should be replaced? } \\
\text { - What size of lathe is most cost effective? }\end{array}$ \\
\hline Priority or Ranking & $\begin{array}{l}\text { Is it more cost effective to invest in new machine tools or a } \\
\text { new HVAC control system? } \\
\text { - We have five proposed investments but can only afford a } \\
\text { selection of them. Which investments do we choose? }\end{array}$ \\
\hline
\end{tabular}

Table 2.2: Appropriate Application of Financial Economic Methods

\begin{tabular}{|c|c|c|c|c|}
\hline & 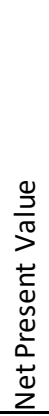 & 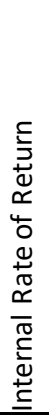 & 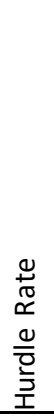 & 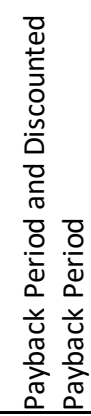 \\
\hline Accept/Reject & $x$ & $x$ & $x$ & $\mathrm{X}^{1}$ \\
\hline Design & $x$ & $\mathrm{X}^{2}$ & & \\
\hline Size & $x$ & $\mathrm{X}^{2}$ & & \\
\hline Priority or Ranking & $\mathrm{X}$ & $x$ & & \\
\hline \multicolumn{5}{|c|}{ 1: Note significant limitations } \\
\hline \multicolumn{5}{|c|}{$\begin{array}{l}\text { 2: Appropriate when incremental discounted costs and benefits are } \\
\text { considered (i.e., the difference in costs/benefits between two } \\
\text { investments). To decide between more than two options, pairwise } \\
\text { comparisons are necessary. }\end{array}$} \\
\hline
\end{tabular}

ASTM E3096: Standard Guide for Definition, Selection, and Organization of Key Performance Indicators for Environmental Aspects of Manufacturing provides a procedure for identifying key performance indicators for the environmental aspects of manufacturing processes. It also provides a procedure for normalizing key indicators, assigning weights, and aligning them with environmental objectives.

One additional standard that can be utilized for evaluating the environmental aspects of manufacturing is ASTM E2986. This guide provides guidance to develop procedures for evaluating environmental sustainability performance of processes in manufacturing. This 
guide addresses a number of issues, including setting boundaries and identifying process and equipment related parameters.

The methods presented here in this guide are designed to make comparisons across a single metric (indicator) of environmental aspects of manufacturing measured as either it's percent change or the unit change resulting from the investment. For simplicity, the guide relies on percent change. To use unit change, the user can simply replace the measure of percent change with the preferred units. ASTM E3096 provides methods of defining and selecting key performance indicators, including a process for aggregating multiple indicators into a single metric.

For this guide, an investment is considered environmentally favorable if the percent change or unit change is less than or equal to zero (i.e., does not increase the environmental impact). It is environmentally unfavorable if the percent change or unit change is greater than zero (i.e., an increase in environmental impact). In the case where Step 1 and Step 2 are being repeated (discussed below), the denominator, environmental impact of the status quo or $E I_{a}{ }^{\prime}$ in the equation below, does not change. Moreover, in the first iteration $E I_{a}{ }^{\prime}$ equals $E I_{a}$; however, in subsequent iterations they will not be equivalent. This is done so that one percentage point of environmental impact always equals the same nominal amount throughout the evaluation. The percent change between two investment options $a$ and $b$ can then be estimated:

Equation 1

where

$$
P C_{e}=\frac{\left(E I_{b}-E I_{a}\right)}{E I_{a}{ }^{\prime}} * 100
$$

$P C_{e}=$ Percent change in environmental impact between option $a$ (i.e., base case) and potential investment option $b$

$E I_{a}{ }^{\prime}=$ Environmental impact of the status quo (i.e., initial base case), which does not change throughout the evaluation

$E I_{a}=$ Environmental impact of investment option $a$

$E I_{b}=$ Environmental impact of investment option $b$

\section{Step 2 - Consolidate Assessments: Evaluate whether there is a Tradeoff}

As presented in the first four columns of Table 2.3, bringing the environmental assessment together with the economic assessment results in a series of potential outcome combinations, referred to as scenarios, for each investment being assessed. Therefore, one might be comparing investments from multiple scenarios (or the same scenario) within a decision type. In the following sections each decision type is discussed with references made to the scenarios in Table 2.3, along with a decision tree for each decision type. The scenarios in the decision trees correspond with those in Table 2.3. 
Accept/Reject Decisions: If a decision is an accept/reject decision for both the environmental and financial assessment (i.e., Scenarios 1.1 through 1.4), then the investment is only acceptable if both assessments are accepted (see Scenario 1.1) and, therefore, no scenarios are compared. This process can be traced in the decision tree in Figure 2.2.

Accept/Reject with Priority/Ranking Decision: If a decision is a combination of accept/reject and ranking/priority (i.e., Scenarios 2.1 through 3.4), then all but two of the scenarios are rejected, as seen in the decision trees in Figure 2.3 and Figure 2.4. There could be multiple investments categorized as Scenario 2.1 or 3.1. If this is the case, then there is a comparison based on either the financial assessment (applicable to Scenario 2.1) or the environmental assessment (applicable to Scenario 3.1).

Design, Size, and Ranking/Priority Decisions: If a decision is a design, size, or ranking/priority decision type (i.e., Scenarios 4.1 through 4.4), then there are four possible scenarios for each investment being evaluated. A series of guidelines need to be followed for this decision type. Scenarios where only one alternative to the status quo is considered (see Figure 2.5) are examined separately from those that have two or more alternatives (see Figure 2.6).

One Alternative: As seen in Figure 2.5, there are three potential outcomes for those instances where there is only one alternative to the status quo. The first potential outcome is when the alternative is ranked better than the status quo in both environmental terms and economic terms (see Scenarios 4.1). In this case, the alternative is preferred to the status quo. The second potential outcome is that the alternative is ranked worse in both

Table 2.3: Consolidating Assessments: Combinations of Outcomes

\begin{tabular}{|c|c|c|c|c|}
\hline Decision Type & Scenario & Environmental Assessment & Economic/Financial Assessment & Action \\
\hline \multirow[t]{4}{*}{ Accept/Reject } & 1.1 & Accept & Accept & Acceptable Investment \\
\hline & 1.2 & Accept & Reject & Reject \\
\hline & 1.3 & Reject & Accept & Reject \\
\hline & 1.4 & Reject & Reject & Reject \\
\hline \multirow{4}{*}{$\begin{array}{l}\text { Environ: } \\
\text { Accept/Reject - } \\
\text { Economic: } \\
\text { Ranking/Priority }\end{array}$} & 2.1 & Accept & Financially Economical & Select on \$ \\
\hline & 2.2 & Accept & Not Financially Economical & Reject \\
\hline & 2.3 & Reject & Financially Economical & Reject \\
\hline & 2.4 & Reject & Not Financially Economical & Reject \\
\hline \multirow{4}{*}{$\begin{array}{l}\text { Environ: } \\
\text { Ranking/Priority } \\
\text { - Economic: } \\
\text { Accept/Reject }\end{array}$} & 3.1 & Environmentally Favorable & Accept & Select on Env. \\
\hline & 3.2 & Not Environmentally Favorable & Accept & Reject \\
\hline & 3.3 & Environmentally Favorable & Reject & Reject \\
\hline & 3.4 & Not Environmentally Favorable & Reject & Reject \\
\hline \multirow{4}{*}{$\begin{array}{l}\text { Design, Size, } \\
\text { Ranking/Priority }\end{array}$} & 4.1 & Environmentally Favorable & Financially Economical & Pairwise Comparison \\
\hline & 4.2 & Not Environmentally Favorable & Not Financially Economical & Reject \\
\hline & 4.3 & Not Environmentally Favorable & Financially Economical & $\begin{array}{l}\text { Consider Tradeoff/ } \\
\text { Pairwise Comparison }\end{array}$ \\
\hline & 4.4 & Environmentally Favorable & Not Financially Economical & $\begin{array}{l}\text { Consider Tradeoff/ } \\
\text { Pairwise Comparison }\end{array}$ \\
\hline
\end{tabular}




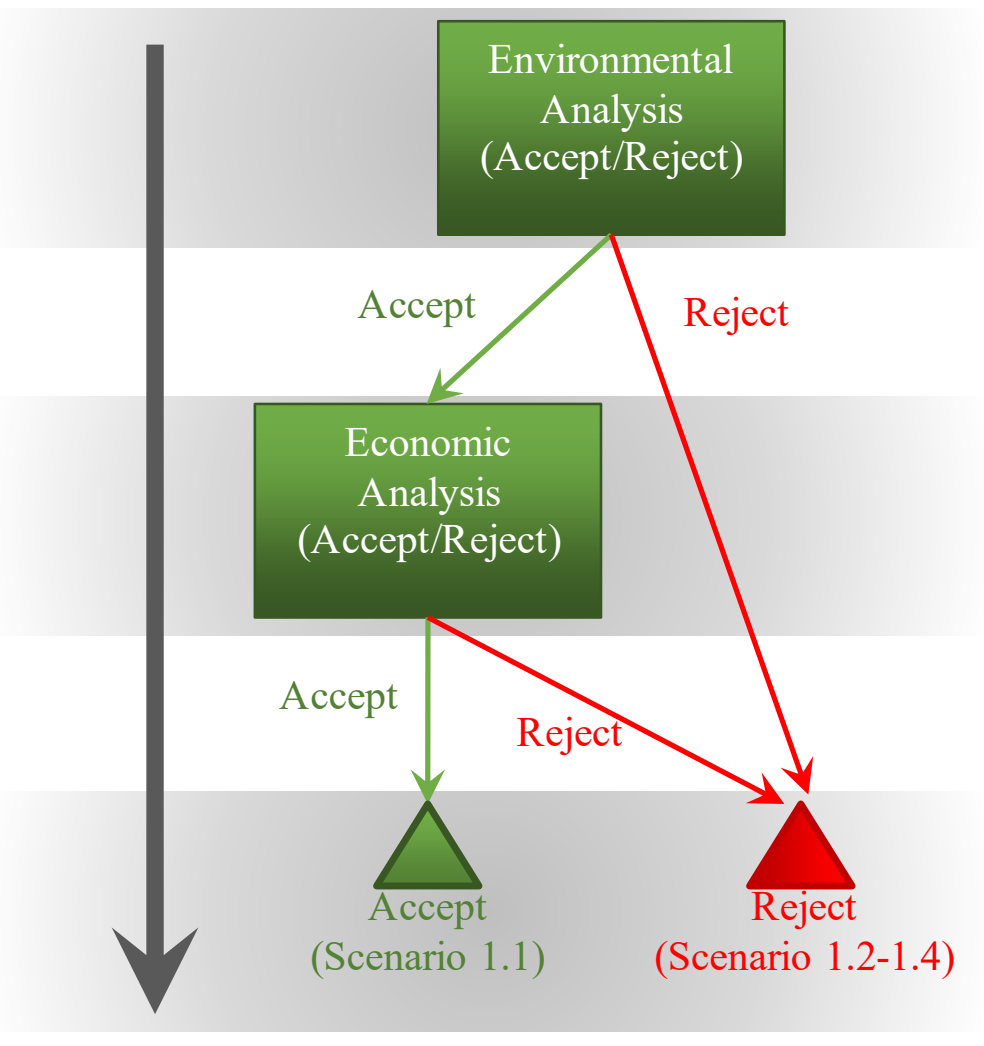

Figure 2.2: Decision Tree for Accept/Reject Decisions

economic and environmental terms (see Scenario 4.2). In this case, the status quo is preferred to the alternative being considered.

The last potential outcome has a tradeoff when compared to the status quo (see Scenarios 4.3 and 4.4). The tradeoff involves one of two situations: 1) an economical investment that increases environmental impact or 2) an investment that is not economical that decreases environmental impact. In this case the user must decide whether the investment with the trad eoff is better or worse than the status quo. A selection of tradeoff metrics is discussed in Step 3 shown in Section 6.6.

Two or more alternatives: For instances where there is more than one alternative to the status quo, the user follows the decision tree in Figure 2.6. Similar to Figure 2.5, if an investment is not economical and it is not environmentally favorable (Scenario 4.2), then that investment is not preferred to the status quo. Investments that are both economical and environmentally favorable must be compared in a pairwise comparison, as discussed below. If there is a tradeoff (Scenarios 4.3 and 4.4), then the user must determine if the tradeoff is preferred to the status quo. A selection of tradeoff metrics is discussed in 

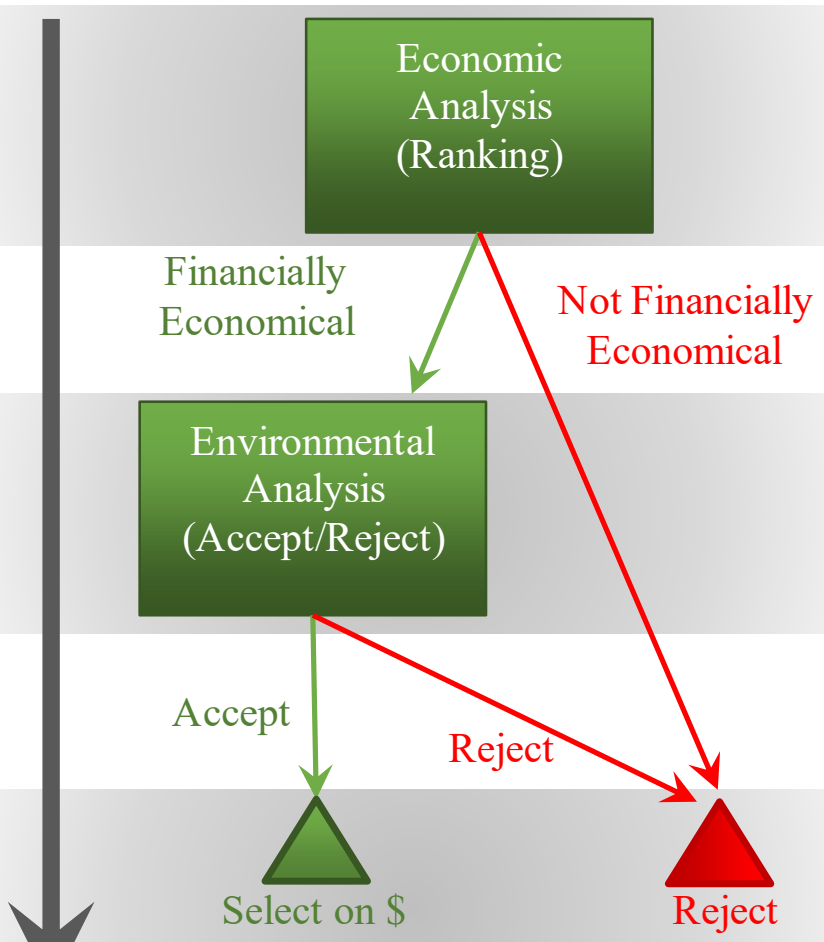

(Scenario 2.1)

(Scenario 2.2-2.4)

Figure 2.3: Decision Tree where Environmental Analysis is Accept/Reject Decision and Economic Analysis is Priority/Ranking Decision

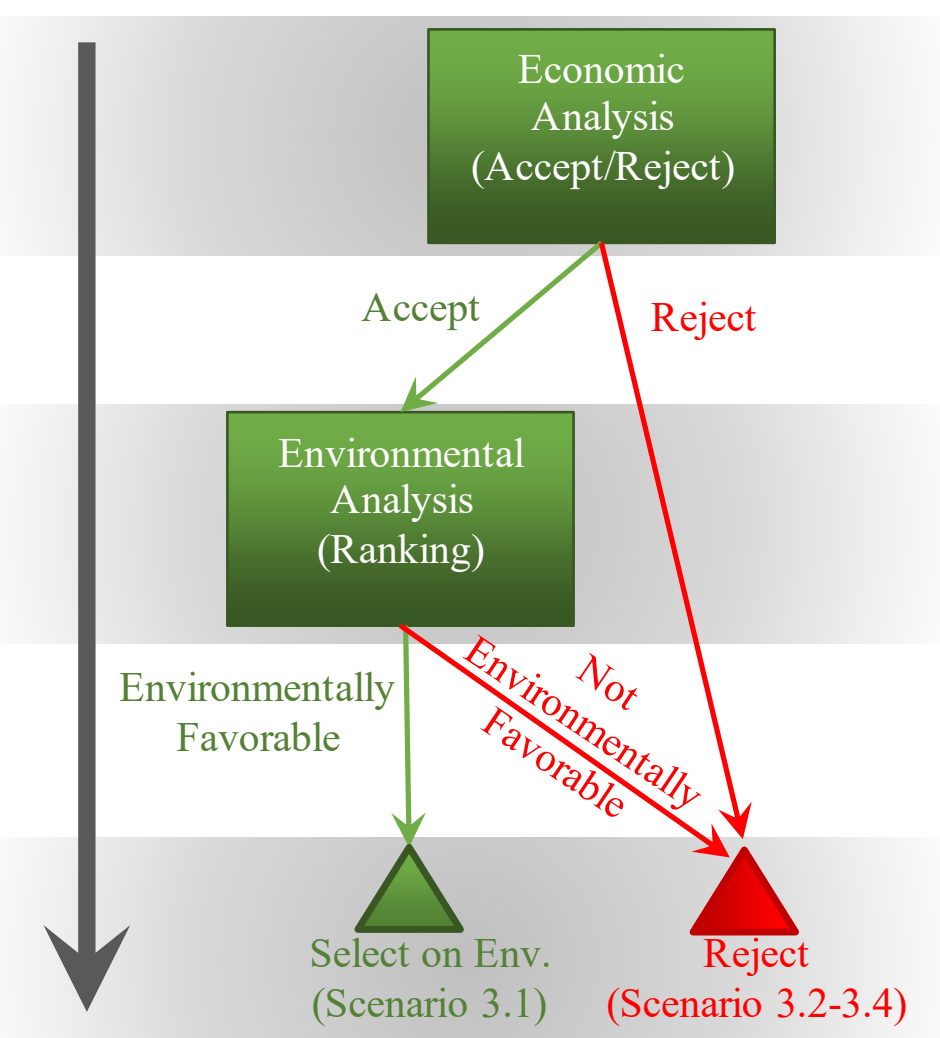

Figure 2.4: Decision Tree where Economic Analysis is Accept/Reject Decision and Environmental Analysis is Priority/Ranking Decision 
Step 3 shown in Section 6.5. If the tradeoff is preferred, then a pairwise comparison must be made between the other alternatives.

Pairwise Comparison: In the case where there are multiple alternative investments, it may be necessary to conduct a pairwise comparison where each investment is compared relative to each of the other investments. The result will rank all the investments. This requires repeating Step 1 and Step 2, but only considering two investments at a time. In each comparison, one investment is selected as the new status quo (i.e., a new base case) while the other investment is treated as a potential alternative investment to the new status quo. Each of the comparisons will result in using Figure 2.5 to determine if the alternative is preferred to the new status quo. Additional investments then can be compared to determine where they rank relative to the others.

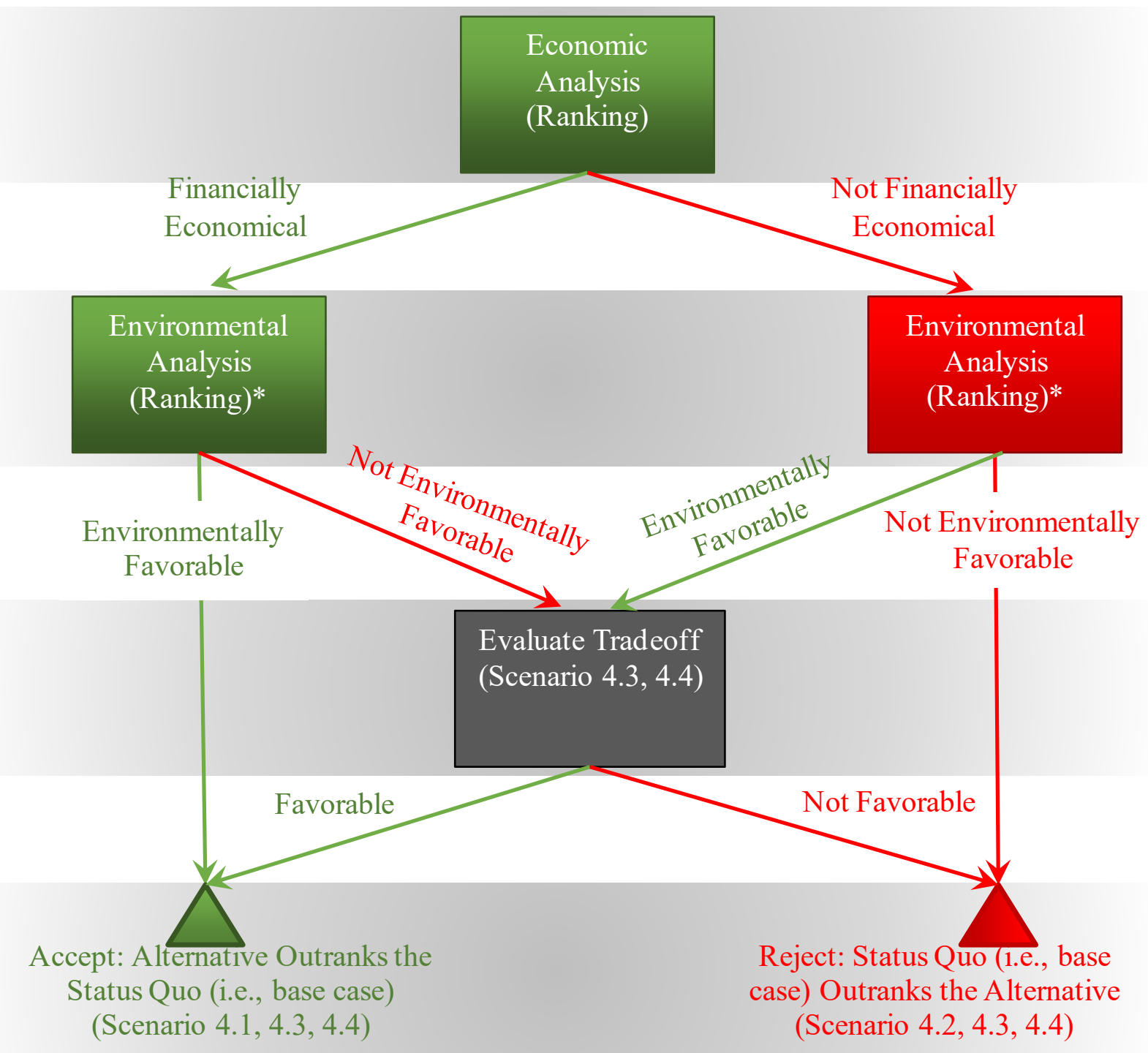

Figure 2.5: Decision Tree for Design, Size, and Ranking/Priority Decisions, One Alternative

\footnotetext{
* These two boxes represent the same environmental a nalysis and not two separate or different a nalyses.
} 
Figure 2.7 illustrates how investments are compared in a pairwise comparison. In this example, it was determined that investments A, B, and C were each preferred over the status quo. A second iteration compared investment $\mathrm{A}$ with investment $\mathrm{B}$, which resulted in determining that $\mathrm{A}$ is preferred to $\mathrm{B}$. A second iteration is needed to determine if investment $\mathrm{C}$ is preferred to $\mathrm{A}$ and/or $\mathrm{B}$, putting it before, between, or after $\mathrm{A}$ and $\mathrm{B}$ in Figure 2.7. Investment $C$ can be compared to investment $A$ to determine if it is ranked $1^{\text {st }}$. If investment $\mathrm{C}$ is not preferred to $\mathrm{A}$, then it must be compared to investment $\mathrm{B}$ to determine whether it is ranked $2^{\text {nd }}$ or $3^{\text {rd }}$. Note that in the case where Step 1 and Step 2 are being repeated, the denominator $E I_{a}{ }^{\prime}$ from the equation from Step 1.2 does not change when using a percent change, as previously discussed.

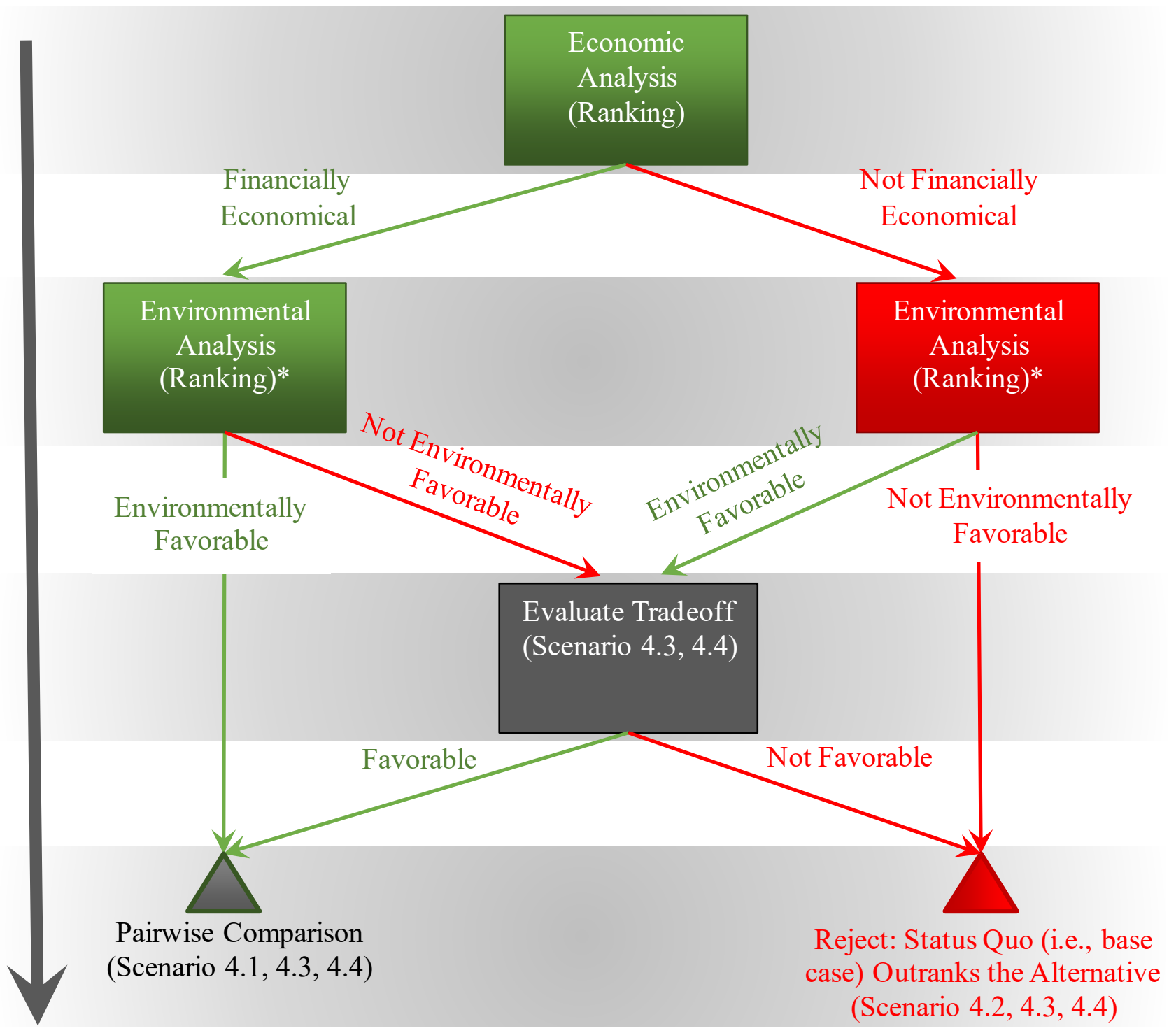

Figure 2.6: Decision Tree for Design, Size, and Ranking/Priority Decisions, Multiple Alternatives

* These two boxes represent the same environmental a nalysis and not two separate or different analyses. 


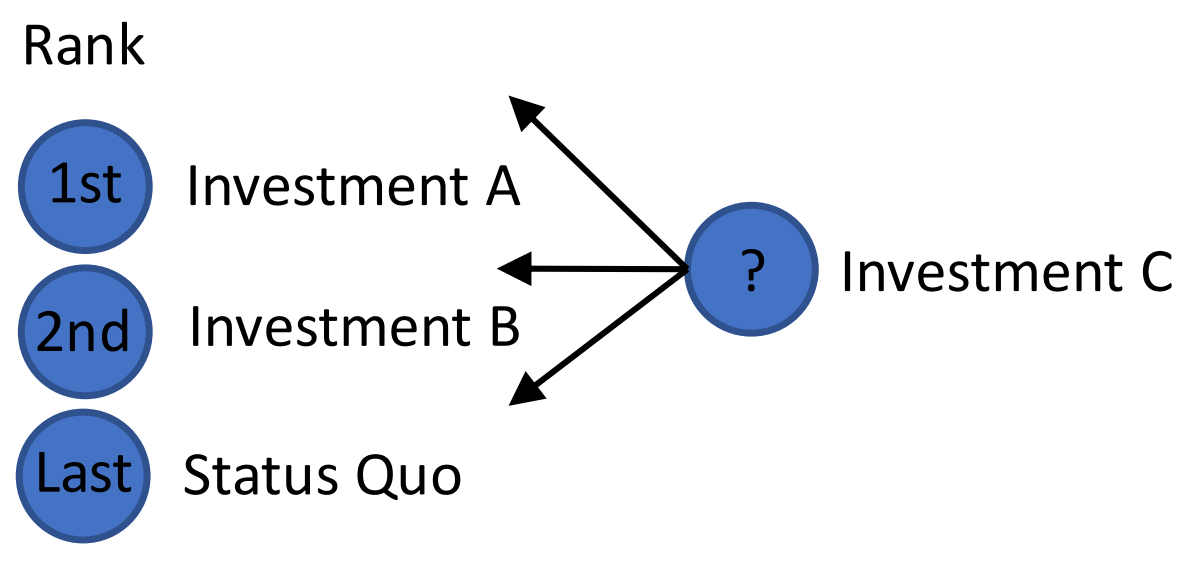

Figure 2.7: Illustration of Pairwise Comparison

Moreover, in the first iteration $E I_{a}{ }^{\prime}$ equals $E I_{a}$; however, in subsequent iterations they will not be equivalent. This is done so that one percentage point of environmental impact always equals the same nominal amount of environmental impact throughout the evaluation.

\section{Step 3 - Evaluate Tradeoff}

A tradeoff exists when: 1) a scenario includes an investment that is not environmentally favorable but is financially economical or 2) a scenario includes an investment that is not financially economical but is environmentally favorable. Each of these has a set of metrics for evaluation.

Not Environmentally Favorable but Financially Economical: There are four metrics that are useful for considering a tradeoff where the investment is not environmentally favorable: maximum impact, the net present value per percent change in environmental impact (NPVP), environmental hurdle rate, and the net present value elasticity (NPVE). Each of these are discussed below.

Not Financially Economical but Environmentally Favorable: There are four metrics that are useful for considering a tradeoff where the investment is not financially economical, but is environmentally favorable: maximum environmental expenditure, maximum environmental expenditure rate (MEER), net present value per percent change in environmental impact (NPVP), and the net present value elasticity (NPVE). Each of these metrics are discussed below.

Maximum Impact: The maximum impact is the largest acceptable increase in environmental impact. It can either be in percent change in impact or in units (e.g., tons of CO2). It is compared to the change in impact for the investment being evaluated and is applicable when the change in environmental impact is positive (i.e., an increase in the impact). If the impact of the investment is greater than the maximum impact, then the investment is rejected or ranked lower when compared to the status quo. For instance, if 
an investment increases the environmental impact by $10 \%$ and the maximum impact for the investor is $5 \%$, then the investment would be ranked lower than the status quo.

Net Present Value per Percent Change in Environmental Impact (NPVP): This value is the average increase or decrease in income brought about by each percentage point change (or unit change) in environmental impact. It is calculated as:

Equation 2

$$
N P V P=\frac{N P V}{P C_{e}}
$$

where

$N P V P=$ Net Present Value per Percent Increase in Environmental Impact

$N P V=$ Net Present Value (see Appendix A1.1)

$P C_{e}=$ Percent change in environmental impact between option $a$ (i.e., base case) and potential investment option $b$ (see Equation 1)

This calculation is only used when there is a tradeoff between cost effectiveness and environmental impact, which occurs when both NPV and $P C_{e}$ are both positive (financially economical but not environmental favorable) or both negative (not financial economical but environmental favorable). In the former situation, higher values are better, as this represents income or cost savings. In the latter situation, lower values are better, as this represents expenditures. Values should not be compared between these two categories, as one represents an expenditure while the other represents income or cost savings.

Environmental Hurdle Rate: The environmental hurdle rate is a value selected by the decision maker and represents the net present value of income or cost savings needed to compel a one percent increase (or one-unit increase) in environmental impact. It is applicable in the case where an investment is financially economical but not environmentally favorable. If the investment's NPVP exceeds the decision maker's environmental hurdle rate, then the investment is considered acceptable or ranked higher when compared to the status quo.

To illustrate the environmental hurdle rate, consider an investment with an NPVP of $\$ 4500$ per percent (or unit) increase in environmental impact. If the decision maker has a $\$ 10000$ environmental hurdle rate, that is, they are willing to increase their environmental impact by $1 \%$ in return for a $\$ 10000$ increase; then, this investment is not preferred. 
Maximum Environmental Expenditure: The maximum environmental expenditure is the total amount the user is willing to pay to reduce environmental impact after all other financial benefits are considered. This metric is intended to be used when the net present value is negative. The maximum expenditure is compared to the absolute value of net present value. If the maximum value is greater than the net present value, then the loss is bigger than the willingness to pay and the alternative is rejected or ranked lower when compared to the status quo. For instance, if an investment has a net present value of $\$-25000$ and the investor has a maximum environmental expenditure of $\$ 30000$, then the investment would be ranked higher than the status quo.

Maximum Environmental Expenditure Rate (MEER): The MEER is a value selected by the decision maker to represent the maximum they are willing to pay to decrease the environmental impact by one percent (or one unit). It is applicable in the case where an investment is not financially economical but is environmentally favorable. If the NPVP is below the MEER, then this investment is considered acceptable or ranked higher when compared to the status quo. For instance, if the NPVP is $\$ 5000$ and the MEER for the investor is $\$ 2500$ per percentage point decrease, then the investment would be ranked below the status quo.

Net Present Value Elasticity (NPVE): The net present value elasticity is the percent increase in net present value per one percent increase in environmental impact. It is calculated as:

Equation 3

$$
N P V E=\frac{\frac{\left(N P V_{b}-N P V_{a}\right)}{N P V_{a}} * 100}{P C_{e}}
$$

where

$N P V_{a}=$ Net present value for the status quo

$N P V_{b}=$ Net present value for investment $\mathrm{b}$

$P C_{e}=$ Percent change in environmental impact between option $a$ (i.e., base case) and potential investment option $b$ (see Equation 1)

This value informs decision makers on the relative tradeoff between the environment and income/cost. For investments that are financially economical but not environmentally favorable, a higher NPVE is considered better. For investments that are environmentally favorable but not financially economical, a lower NPVE is better. The NPVE can be compared between investments, but the NPVE for investments that are financially economical but not environmentally favorable should not be compared with the NPVE for investments that are environmentally favorable but not financially economical. 


\section{Step 4 - Sensitivity Analysis}

The techniques discussed in the previous section of the guide are what are known as deterministic techniques, meaning that there are single values assumed for calculations incorporated into the analysis. Deterministic techniques assume the manufacturer knows with complete certainty all the variables in the relevant equation, whether they are future payment streams or interest/discount rates. Every part of every equation is assumed to be known with absolute confidence.

In most situations that a manufacturer faces, at least some of the values needed to make a decision are not completely transparent or may be known with only partial certainty.

To account for this uncertainty, the manufacturer can turn to probabilistic techniques such as a sensitivity analysis. Sensitivity analysis quantifies the change in results due to variation in one or more input values.

For example, suppose the manufacturer is deciding whether to invest in some capital machinery, and will base the decision on the NPV. Assume that a manufacturer faces uncertainty about the opportunity cost of capital, which affects the discount rate for an investment. The choice of discount rate may determine that investment decision. To account for the uncertainty, the manufacturer can use the concept of a risk-adjusted discount rate (RADR). By assigning probabilities to each of a range of discount factors, the manufacturer can perform a more sophisticated analysis than by simply choosing a discount rate deterministically. Suppose that the manufacturer allows for $r$, the discount rate, to take a range of values. Assume $\mathrm{r}$ could be $5 \%, 6 \%$, or $7 \%$. Further, assume the probability of each of these three values is equal, at one-third probability each. By calculating each of the $r$ 's and assigning a one-third probability to them, the manufacturer will have a better understanding of the range of possibilities of investing in the capital machinery.

A more specific type of sensitivity analysis, and one that is commonly deployed when dealing with probabilistic decision-making is the Monte Carlo analysis. The Monte Carlo method uses repeated random sampling to generate simulated data to use with a mathematical model. Monte Carlo analysis can be performed using a variety of computer software packages.

Monte Carlo analysis operates in the following manner: Each variable in the model is assigned a likely range of outcomes, based on prior data analysis. Each time the model is run, the computer program will rand omly assign values to those variables based on user specified distributions and ranges. The model is typically run for thousands of iterations, with new randomly generated input variables each time. The outcomes across these iterations are tabulated and summarized into a probability distribution.

Rather than a deterministic base case scenario, a Monte Carlo simulation typically produces a range of outcomes that can be used to develop a distribution. 
The caveat with Monte Carlo is that the results are shaped by the underlying assumptions. As in any model, the accuracy of the assumptions is key. With a Monte Carlo simulation, the ranges of possible values assigned to each variable constitute a critical set of assumptions on which the whole undertaking rests, along with the methodology for converting random numbers generated by the computer into values within these ranges.

The great benefit of the Monte Carlo analysis is that the values will be selected randomly using the algorithm of the chosen software package. Because there is difficulty in approximating randomness, a computer package can do a relatively accurate job of approximating randomness (although it will be just an approximation since no computer program can generate true randomness).

One of the challenges that arises in sensitivity/uncertainty analysis is that some investments might end up being recategorized as a different scenario from Table 2.3. The probabilistic nature of the analysis means that the underlying investments will be categorized in different ways, depending on the state of the world generated by the changing scenarios. Currently, there is no known software package that can be applied to account for this issue; thus, one would have to develop their own coded model that makes this calculation. The outcome would estimate the ranking of each investment for each iteration.

Monte Carlo analysis is further discussed in Section 3.1 of NIST Advanced Manufacturing Series 200-5. ${ }^{1}$ NIST's Monte Carlo tool can be used to implement this type of analysis.

Sensitivity Analysis Example: Assume that a piece of capital machinery in a manufacturer's plant will wear out after some number of years. However, the manufacturer does not know for sure when the machinery will wear out, but there is reason to believe that the machinery could fail in any year from year 4 to year 8 . Further, suppose there is a probability of occurrence associated with each year of obsolescence, which in this scenario is assumed to be known for each of the five years under consideration. For this illustration, the replacement cost does not vary based on the year of replacement and is always $\$ 100000$. A sensitivity factor (created exclusively for this example) is then applied to each replacement cost by year. The sensitivity factor can be generated through any number of software packages. This in turn provides the expected present value of the cost for each year.

By applying sensitivity analysis, the manufacturer can evaluate the range of possible replacement costs, based on the year when the capital machinery finally wears out and can budget for those scenarios, thus reducing the risk to the firm. Looking at Table 2.4, notice that in this instance the sum of the probabilities of a failure occurring in the second column totals one. Furthermore, this example assumes that the replacement cost is always the same, no matter what year it was incurred. The values generated in the fourth column are artificial examples generated for the purposes of this example. What is

${ }^{1}$ Thomas, Douglas. 2017. Investment Analysis Methods: A Practitioner's Guide to Understanding the Basic Principles for Investment Decisions in Manufacturing. NIST Advanced Manufacturing Series 200-5.https://doi.org/10.6028/NIST.AMS.200-5 
important to note is that the product of the replacement cost and the sensitivity values of present value savings generate the expected present value of cost.

Table 2.4: Sensitivity Analysis Example

\begin{tabular}{cllll}
\hline $\begin{array}{l}\text { Year for Capital } \\
\begin{array}{l}\text { Machinery } \\
\text { Replacement }\end{array}\end{array}$ & $\begin{array}{l}\text { Probability } \\
\text { of } \\
\text { Occurrence }\end{array}$ & $\begin{array}{l}\text { Replacement } \\
\text { Cost }\end{array}$ & $\begin{array}{l}\text { Sensitivity of } \\
\text { Present Value } \\
\text { Savings }(10 \% \\
\text { Discount } \\
\text { Rate) }\end{array}$ & $\begin{array}{l}\text { Expected } \\
\text { Present } \\
\text { Value of } \\
\text { Cost }\end{array}$ \\
\hline 4 & 0.2 & 100000 & 0.2 & 400 \\
5 & 0.3 & 100000 & 0.225 & 6750 \\
6 & 0.1 & 100000 & 0.456 & 4560 \\
7 & 0.15 & 100000 & 0.178 & 2670 \\
8 & 0.25 & 100000 & 0.676 & 16900 \\
\hline
\end{tabular}

\section{Step 5 - Rank the Investments}

The last step of this process is to rank the investments based on the analysis. Investments falling into Scenario 1.1 through 1.4 in Table 2.3 will either be accepted or rejected. For the other decision categories, the user selects one or more investments based on the ranking of the investments. 


\section{References}

ASTM. E1057: Standard Practice for Measuring Internal Rate of Return and Adjusted Internal Rate of Return for Investments in Buildings and Building Systems. West Conshohocken, PA.

ASTM. E1369: Standard Guide for Selecting Techniques for Treating Uncertainty and Risk in the Economic Evaluation of Buildings and Building Systems. West Conshohocken, PA.

ASTM. E2114: Standard Terminology for Sustainability Relative to the Performance of Buildings. West Conshohocken, PA.

ASTM. E2921: Standard Practice for Minimum Criteria for Comparing Whole Building Life Cycle Assessments for Use with Building Codes, Standards, and Rating Systems. West Conshohocken, PA.

ASTM. E2986: Standard Guide for Evaluation of Environmental Aspects of Sustainability of Manufacturing Processes. West Conshohocken, PA.

ASTM. E2987/E2987M: Standard Terminology for Sustainable Manufacturing. West Conshohocken, PA.

ASTM. E3096: Standard Guide for Definition, Selection, and Organization of Key Performance Indicators for Environmental Aspects of Manufacturing Processes. West Conshohocken, PA.

ASTM. E3200: Standard Guide for Investment Analysis in Environmentally Sustainable Manufacturing. West Conshohocken, PA.

ASTM. E833: Standard Terminology of Building Economics. West Conshohocken, PA.

International Organization for Standardization. ISO 14025: Environmental Labels and Declarations - Type III Environmental Declarations - Principles and Procedures. Geneva, Switzerland.

International Organization for Standardization. ISO 14040: Environmental Management - Life Cycle Assessment - Principles and Framework. Geneva, Switzerland.

International Organization for Standardization. ISO 14044: Environmental management - Life cycle assessment -- Requirements and guidelines. Geneva, Switzerland.

International Organization for Standard ization. ISO 14049: Environmental management - Life Cycle Assessment -- Illustrative Examples on How to Apply ISO 14044 to Goal and Scope Definition and Inventory Analysis. Geneva, Switzerland.

International Organization for Standardization. ISO 14067: Greenhouse gases -- Carbon Footprint of Products -- Requirements and Guidelines for Quantification and Communication. Geneva, Switzerland. 
International Organization for Standardization. ISO 21930: Sustainability in Buildings and Civil Engineering Works -- Core Rules for Environmental Product Declarations of Construction Products and Services. Geneva, Switzerland.

Thomas, Douglas. 2017. Investment Analysis Methods: A Practitioner's Guide to Understanding the Basic Principles for Investment Decisions in Manufacturing. NIST Advanced Manufacturing Series 200-5. https://doi.org/10.6028/NIST.AMS.200-5 


\section{Appendix A: Economic Methods}

Below is a discussion of the methods for an economic analysis. Further discussion of these methods can be found in NIST Advanced Manufacturing Series 200-5. ${ }^{2}$

A1.1 Net Present Value (NPV): The basic formula in the manufacturer's financial toolkit is the net present value formula. The net present value represents all the future earnings from undertaking a project, discounted by some current interest rate, minus the initial project costs. It is important to note that the future earnings can be either positive or negative. The formula for net present value (NPV) can be expressed in this manner:

Equation 4

$$
N P V=\sum_{t=1}^{T} \frac{C_{t}}{(1+r)^{t}}-C_{0}
$$

Where

$C_{t}=$ net cash inflow during the period t relative to the status quo (i.e., base case)

$C_{o}=$ total initial investment costs

$r=$ discount rate, and

$t=$ time period of cash flow

NPV Discussion: The net present value concept can be broken down in the following manner, thinking about a hypothetical investment decision. Any investment has initial startup costs - from hiring workers to renting a building to investing in capital machinery. These startup costs incurred by the investment must be subtracted from any gain generated by the investment.

An investment may have an effective life of any length of time, represented by the number of time periods, $t$, in Figure A-1. All the net cash inflows during that period must be accounted for. Each cash inflow must be discounted to present value and then the total of discounted cash flows is summed up for the stated time period.

Note that this version of the NPV formula above assumes, for the sake of simplicity, that the investment discount rate is a constant number. By varying the discount rates while keeping the net cash inflow, total initial costs, and number of time periods constant, the manufacturer can determine at what discount rates an investment becomes viable (net positive cash flows). One can also keep the discount rate constant and vary the time period $t$, to determine when the proposed investment will deliver the requisite cash flow needed to justify an investment.

\footnotetext{
${ }^{2}$ Thomas, Douglas. 2017. Investment Analysis Methods: A Practitioner's Guide to Understanding the Basic Principles for Investment Decisions in Manufacturing. NIST Advanced Manufacturing Series 200-5.https://doi.org/10.6028/NIST.AMS.200-5
} 
NPV is the first and most fundamental of the four deterministic decision-making tools that are available to the manufacturer. Unlike the other techniques presented in the following sections, it can be applied to every possible decision type from numerical rankings to simple accept/reject decisions; however, alone it does not reveal all aspects of an investment comparison.

The advantage of NPV is its relative simplicity to calculate. The disadvantage is that it does not consider the scale of the investment. For example, an investment may have a positive NPV, but it may not be selected because it might consume too many resources that could be used in an investment of larger scale where the absolute percent returns on investments is greater but the NPV might be smaller.

NPV Example: Assume that a manufacturer is contemplating an investment with an initial investment outlay of $\$ 200000$. The investment is projected to last for six years and will have variable annual cash inflows and outflows, as shown in Table A-1 and Figure A-1. In the last year of the investment, the cash outflows will surpass the inflows and lead to a negative net cash flow. Assume a discount rate of $4 \%$.

Table A-1: Example Cash Inflows and Outflows by Year for NPV Calculations (Dollars)

\begin{tabular}{lcll}
\hline Year & $\begin{array}{l}\text { Cash } \\
\text { Inflows }\end{array}$ & $\begin{array}{l}\text { Cash } \\
\text { Outflows }\end{array}$ & $\begin{array}{l}\text { Net Cash } \\
\text { Flow }\end{array}$ \\
\hline Initial Investment & - & 200000 & -200000 \\
Year1 & 30000 & 8000 & 22000 \\
Year2 & 70000 & 7000 & 63000 \\
Year3 & 60000 & 15000 & 45000 \\
Year4 & 59000 & 9000 & 50000 \\
Year5 & 60000 & 4000 & 56000 \\
Year6 & 5000 & 9000 & -4000 \\
\hline
\end{tabular}

Given the net cash flows and the discount rate, the net present value is calculated to be $\$ 205$ 012.59. Subtracting the initial investment of \$200 000.00 from the present value of future cash flows, we get a positive net present value of $\$ 5012.59$. A positive net present value implies the investment is economical.

A1.2 Internal Rate of Return (IRR): The internal rate of return is the discount rate for which the NPV is zero dollars $(\$ 0.00)$. This is the rate that your money would have to earn in another investment for you to be ind ifferent to the investment. The term "IRR" is often used interchangeably with the term, "economic rate of return," or "ERR." IRR is used more commonly by corporate practitioners and academics so that is the term that will be utilized in this guide. 


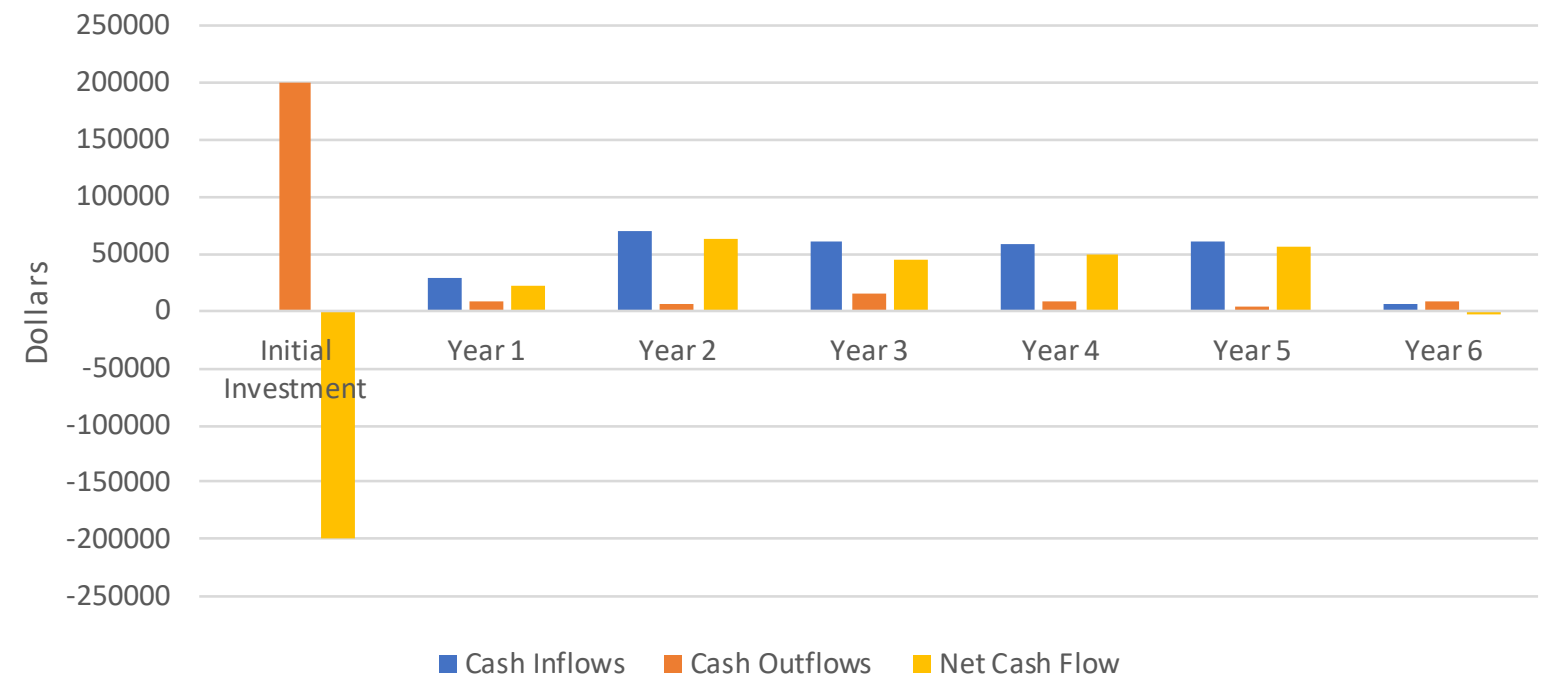

Figure A-1: Example of Net Cash Flows by Year

The concept of the internal rate of return relies on the basic NPV formula. But the difference with NPV is that the manufacturer is now solving for the $r$ and NPV is set to zero. The decision maker is trying to ascertain the rate of return so that the discounted cash flows equal the initial project outlay. The IRR is the solution for $r$ for which:

Equation 5

$$
N P V=\sum_{t=1}^{T} \frac{C_{t}}{(1+r)^{t}}-C_{0}=0
$$

IRR Discussion: Due to the nature of this calculation, individuals use software or trial and error to identify the internal rate of return (i.e., select varying discount rates for NPV to identify the value where the net present value equals zero). It is also possible to solve for IRR graphically by plotting IRR's on the $x$-axis and a range of NPV's on the y-axis. It should also be noted that the IRR equation can produce multiple values for $r$. This often occurs when at least one future inflow is succeed ed by an outflow. This might occur when a project loses money in certain years and has negative cash flows for those years. There are also scenarios where there is no solution for $r$. In these scenarios, it makes sense to use an alternate measure, like the net present value formula.

IRR can be thought of as the investment's growth rate. Note common practice is to drop the NPV calculation in the formula and simply substitute $\mathrm{C}_{\mathrm{o}}$ on the left-hand side of the equation and solve to find the exact total initial costs. 
There are advantages and disadvantages to the IRR methodology. One disadvantage that has already been noted is that it is relatively more difficult to calculate than the NPV. The calculation can become even more difficult if one assumes that the discount rate varies over the relevant period. For example, the rate can be one value in years one and two, another one in years three and four, and still another one in year five. Most solutions for IRR rely on one of two methods - trial and error or graphical solutions.

Another disadvantage of IRR is that it fails to take scale into account. Although a manufacturer might be concerned about the rate of return, the absolute size of the investment may be of importance. For example, a \$1 million project and a \$100 million project that return the same IRR require different levels of initial investment. Because IRR is insensitive to scale, it can mislead manufacturers about issues of scale and true project costs.

The concept of the "hurdle rate," has not been discussed yet, but one advantage of IRR is that it allows the manufacturer to bypass selecting or calculating a discount rate for estimating NPV by comparing the IRR to the hurdle rate (although the IRR is, typically, compared to a discount rate). The calculation of the IRR also shows the exact rate of return for a project. The concept of the hurdle rate involves a discussion of the weighted average cost of capital, which depends on the mix of equity and debt that a company issues - usually, a concern for larger manufacturers that are organized as corporations. However, a smaller or non-corporate manufacturer can zero out the equity section of the equation or make whatever modification best describes their mode of organization.

The IRR concept can be partially modified and divided into two related concepts. This follows the practice set out in ASTM E1057 by distinguishing between the unadjusted IRR and the adjusted IRR (AIRR).

IRR assumes that net cash flows are reinvested at a rate equal to that earned on the original investment, whereas the AIRR measure relies on the fact that net cash flows are reinvested at a rate different from that earned on the original investment.

The IRR method will diverge from the values generated by an incremental "benefits-tocost ratio" (BCR) or a "savings-to-investment (SIR) ratio" in certain scenarios. The BCR is the ratio of the proposed benefits subject to the costs of an investment and like IRR, is calculated using trial and error or software methods. The SIR quantifies the savings realized over the life of an investment relative to the initial investment costs. The SIR is $\mathrm{BCR}$ in a scenario where one is choosing between projects based on reduced costs instead of realized benefits.

IRR Example: An example of IRR can be derived using the same numbers as the NPV example. We are now solving for the $r$ in the equation. The linkage between IRR and NPV can be seen in Table A-2. 
Table A-2: IRR Decision Matrix

\begin{tabular}{l}
\hline If IRR $>$ Discount Rate, NPV will be $>0$ \\
If IRR $<$ Discount Rate, NPV will be $<0$ \\
If IRR $=$ Discount Rate, NPV will $=0$ \\
\hline
\end{tabular}

Solving through trial and error (or a software package), we can determine the internal rate of return is $4.83 \%$ for the example previously discussed in Table A-1 and Figure A-1.

However, as noted above, there are situations where multiple values of IRR may yield a the solution. Take the example in Table A-3, which has an initial investment cost of $\$ 70$ 000

Table A-3: Example Cash Inflows and Outflows by Year for NPV Calculations

\begin{tabular}{llll}
\hline Year & $\begin{array}{l}\text { Cash } \\
\text { Inflows }\end{array}$ & $\begin{array}{l}\text { Cash } \\
\text { Outflows }\end{array}$ & $\begin{array}{l}\text { Net Cash } \\
\text { Flow }\end{array}$ \\
\hline Initial Investment & - & 70000 & -70000 \\
Year1 & 80000 & 8000 & 72000 \\
Year2 & 40000 & 7000 & 33000 \\
Year3 & 60000 & 45000 & 15000 \\
Year4 & 59000 & 57000 & 2000 \\
Year5 & 60000 & 19000 & 41000 \\
Year6 & 10000 & 260000 & -250000 \\
\hline
\end{tabular}

In this example, due to the highly negative cash outflow of the last year of $-\$ 250000$, when the NPV is set to zero and $r$ is solved, there are multiple solutions. Between these two values, the NPV is positive. Outside of the range between these two values, the NPV is negative. An alternative is to use the modified internal rate of return (MIRR), which yields only one solution and may be quite different than the corresponding IRR value(s). The MIRR is used most in finance because it relies on more realistic assumptions than the IRR formula. Namely, the IRR formula assumes that the initial investment cost is funded at the same level as the general rate of return faced by the firm. The MIRR formula can be expressed in this manner:

Equation 6

$$
M I R R=\sqrt[n]{\frac{F V(\text { Positive Cash Flows })}{P V(\text { Initial Expenditures })}}-1
$$


Recall that $n$ is equal to the number of periods and FV refers to the future value and PV to the present value.

A1.3 Payback Period: The payback period is the time interval required to recover the costs associated with investing in a project. The payback period is almost always expressed in terms of years. The formula used to calculate the payback period of an investment depends on whether the cash flow per period from the investment is uniform or not. In case the cash flows are uniform, the formula to calculate payback period can be expressed as:

Equation 7

$$
\text { Payback Period }=\frac{\text { Initial Investment }}{\text { Cash Inflow per Period }}
$$

One can design the payback period formula so that the cash flows grow by a constant rate (or decrease by a constant rate). The formula for discounted payback period with constant cash flows is:

Equation 8

$$
D P P=\frac{\ln \left(\frac{1}{1-\left[\frac{I * r}{P C F}\right]}\right)}{\ln (1+r)}
$$

where

DPP $=$ Discounted Payback Period

$I=$ The Initial Investment Amount

$r=$ Discount rate

$\mathrm{PCF}=$ Periodic Cash Flow

When the cash flows are uneven (or non-uniform), the DPP formula in the equationError! Reference source not found. above cannot be utilized. However, the underlying concept of the payback period remains the same. The manufacturer must simply add the present values of cash flows for each year until the aggregate of those uneven cash flows matches the original project costs. The payback period can be found by solving for $t$ in the following equation:

Equation 9

$$
\sum\left(\frac{N C F_{t}}{(1+r)^{t}}\right)=\text { Initial Investment }
$$

where 
$N C F=$ Net cash flows for time period $t$

$r=$ discount rate for time period $t$

$t=$ the number of time periods

It is important to note that there might be more than one solution to this equation with the minimum solution being the payback period.

Payback Period Discussion: The payback period is the length of time required to recover the cost of a project or undertaking. Note that the common use of payback period, to look for positive cash flows, can also be easily utilized where cash flows are negative, and the manufacturer wishes to determine how long to continue an investment until cash flows are recovered.

The payback period is useful from a risk perspective, since it gives a simplified picture of the amount of time that the initial investment will be at risk. The drawback is that if the manufacturer were to analyze a prospective investment using the payback method, one would tend to accept those investments having rapid payback periods and reject those having longer ones regardless of the overall net present value and/or return on investment.

Payback period is more useful in industries where investments become obsolete very quickly, and where an expedited and full return of the initial investment is the primary concern. Choosing between two alternate investments with short durations is an optimal use of payback period.

Asset life span is another consideration with payback period. If an asset's useful life expires immediately after it pays back the initial investment, then there is no opportunity to generate additional cash flows. The payback method does not incorporate any assumption regarding asset life span.

The concept also does not consider the presence of any additional cash flows (i.e., inflows or outflows) that may arise from an investment in the periods after full payback has been achieved.

The formula does not account for the multitude of cash flows associated with a capital investment. For example, cash investments may be required at several stages, such as cash outlays for periodic upgrades. Also, cash outflows may change significantly over time, varying with customer demand and the amount of competition.

The payback method focuses solely upon the time required to pay back the initial investment; it does not track the ultimate profitability of an investment. Thus, the method may indicate that an investment having a short payback period with no overall 
profitability is a better investment than one with a long-term payback that has substantial long-term profitability.

The payback period formula is focused on a specific project or product line and does not account for the output of the entire system, only a specific operation.

A1.4 Hurdle Rate: The hurdle rate is the minimum required rate of return for the manufacturer that is acceptable for them to accept an investment. It is a concept similar to the internal rate of return. The "hurdle" is a financial barrier (a minimally acceptable interest rate) that must be crossed to justify the investment acceptance decision on the part of the manufacturer. The choice of the hurdle rate, similar to the discount rate, may vary by user preference. A common hurdle rate that is used is the weighted average cost of capital $(W A C C)$. The formula is often expressed in this manner:

Equation 10

$$
W A C C=\frac{E}{V} * R_{e}+\frac{D}{V} * R_{d} *(1-T)
$$

where

$R_{e}=$ cost of equity

$R_{d}=$ cost of debt

$E=$ market value of the firm's equity

$D=$ market value of the firm's debt

$V=E+D=$ total market value of the firm's financing (equity and debt)

$T=$ effective corporate tax rate

The $W A C C$ is often utilized as a hurdle rate because it is well understood. It also takes into consideration several factors not usually considered by the other deterministic techniques - like taxes and the mixture of debt and equity that a firm uses to fund itself.

Notice that the ratio $E / V$ is the proportion of financing that is equity, and that the ratio $D / V$ is the proportion of financing that is debt. Thus, the determination of the hurdle rate depends on knowing the proportions of each firm that is devoted to each kind of financing.

$R d *(1-T)$ represents the after-tax cost of debt - i.e., the after-tax rate of return which the debthold ers need to earn until the maturity of the debt. WACC assumes no change in the capital structure, an assumption that is hard to sustain in practice due to firms constantly changing the mix of capital they use to finance themselves and their operations. Cost of debt of a company is based on the yield to maturity of the relevant instruments. If no yield to maturity is available, the cost can be estimated using the instrument's current yield. After-tax cost of debt is included in the calculation of WACC 
because debt offers a tax shield. This reduction in taxes is reflected in reduction in cost of debt capital.

In practice, WACC is difficult to calculate. Because certain elements of the formula, like cost of equity, are not consistent values, there can be a great deal of variation within the formula. As such, while WACC can often help lend valuable insight into a company, one should always use it along with other tools. 


\section{Appendix B: Examples}

This appendix illustrates the method for environmentally sustainable investment analysis. It does not introduce any new concepts, but rather offers a series of illustrative examples to show how the economic and environmental concepts would work in tandem.

The most crucial point that needs to be made at the outset of this appendix is that it cannot decide for the manufacturer whether environmental considerations will predominate over economic considerations or vice versa. It is up to each individual manufacturer to decide how to weight economic and environmental decision-making. This appendix merely provides comprehensive examples showcasing all the financial formulas that were defined in the standard guide for E60. Listed are 10 examples and the concepts that they illustrate:

1. NPV for a single year

2. NPV for multiple years

3. Maximum impact

4. Environmental hurdle rate and NPVP

5. NPV, IRR, environmental hurdle rate, and NPVP

6. IRR

7. Payback period and maximum impact

8. Payback period and maximum impact

9. Maximum impact, hurdle rate, and WACC

10. Multiple investment alternatives, MEER, NPV, IRR, and pairwise comparison

Example 1 (NPV for a single year): Suppose we have a manufacturer who is looking to open a new factory that manufactures widgets. Her finance and strategy teams, after performing market scoping and forecasting activities, have convinced her that there is a robust market for widgets and that she should construct a new factory to meet this demand.

However, any new project has its costs as well as its benefits. The manufacturer in our case faces two sets of costs when deciding whether to open her widget factory - namely, economic costs and environmental impacts. The economic costs can consist of, but are not limited to, the initial investment costs (which can include planning, raising funds to purchase capital and labor, and doing market studies to focus on product lines), operating costs once the business is up and running and the miscellaneous costs that are generated by any business (from legal/regulatory compliance costs to the costs of paying taxes).

The environmental impacts are also of importance. Any business of any scale will generate environmental impact of some sort - whether it is the emissions generated by a manufacturing plant or the land and water impact that comes from converting raw materials into manufactured goods.

Let us return to the example of the manufacturer of the widgets. When her finance and strategy team approach her with a study showing that it will be profitable to manufacture 
the widgets, the first question the manufacturer might ask is what is the expected net present value (NPV) of the project. If the NPV is negative, the project will probably not be undertaken (unless the manufacturer believes it is worth taking losses to establish a presence in a crucial financial market).

Suppose that the marketing and production team tells the manufacturer that they expect that the widget manufacturing program will bring in $\$ 5$ million at the end of the fifth year. The project will cost $\$ 2$ million in initial costs to launch the widget manufacturing program. If the manufacturer faces an effective discount rate of $4 \%$, we can calculate the net present value of the program using Equation 4.

$$
\mathrm{NPV}=\sum_{\mathrm{T}=1}^{5} \frac{5000000}{(1+.04)^{5}}-2000000=2109635.53
$$

The manufacturer will most likely proceed with this project under these circumstances given a positive net present value that exceeds $\$ 2$ million. This scenario deals with an unrealistic case, however. Most projects often have cash flows throughout their life, not just at the end of the project.

Example 2 (NPV for multiple years): Let us assume another case where there are cash flows for each of the five years of the project (see Table B-1), not just the final year. We also assume negative cash flows in certain years due to losses from the manufacturing line, a not unrealistic assumption. We will continue to use a discount rate of 4 percent and a project life of five years and an initial investment of $\$ 2000000$.

Table B-1: Annual Cash Flows for Example 2

\begin{tabular}{|c|c|}
\hline Year 1 & 1000000 \\
\hline Year 2 & 4000000 \\
\hline Year 3 & -2000000 \\
\hline Year 4 & -3000000 \\
\hline Year 5 & 6000000 \\
\hline
\end{tabular}

Using the NPV formula, we get (in dollars):

$$
\begin{aligned}
\mathrm{NPV}=\sum_{\mathrm{T}=1}^{5} \frac{1000000}{(1+.04)^{1}}+\frac{4000000}{(1+.04)^{2}}+\frac{-2000000}{(1+.04)^{3}}+\frac{-3000000}{(1+.04)^{4}}+\frac{6000000}{(1+.04)^{5}}-2000000= \\
3248920.66
\end{aligned}
$$

In this scenario with cash flows in each year, even with the negative cash flow of the third and fourth years, the net present value of the project is still positive (and larger than the net present value in our previous example where there was only a net positive cash flow in the final year). The NPV formula is the foundational formula of finance and it can be modified to deal with any plausible scenario, including more complicated scenarios when there are multiple cash flows within one year, not just the end of that year. 
The NPV formula is highly useful. The manufacturer can calculate the NPV's of several rival projects and choose the one that provides her with the highest projected return. But using NPV has some drawbacks as well. For example, it d oes not consider the scale of the proposed project. A manufacturing project can have a higher NPV than another project, yet it might require greater initial investment $\left(\mathrm{C}_{0}\right)$, funds that the manufacturer might not have on hand at the moment. The NPV's simplicity in calculation also comes with drawbacks, which is true of every deterministic financial formula that will be discussed in this section.

Example 3 (maximum impact): If the manufacturer wants to take environmental considerations into account, they can use equation 1.

Now suppose that in manufacturing the widgets, the factory releases carbon emissions, a scenario that faces nearly all manufacturers who do not use clean energy sources. Carbon emissions are often measured in carbon dioxide equivalents, which are expressed in part per million by volume, usually known by the abbreviation of ppmv.

Let us use the formula above to calculate the $P C_{e}$. The status quo is the case where the manufacturer sticks to its regular activities and does not manufacture the widgets. That state is denoted by $E I_{a}{ }^{\prime}$. Suppose that in the status quo scenario, the manufacturer releases 10 million ppmv.

Suppose further that the manufacturer's chief carbon scientist has estimated the new wid get production line has carbon emissions of 15 million ppmv, which is 5 million more ppmv than the status quo. Using Equation 1, we can calculate the environmental impact of producing widgets:

$$
P C_{e}=\frac{(15000000-10000000)}{10000000} * 100
$$

The $P C_{e}$, or percentage change in environmental impact, is thus $50 \%$. Thus, the new widget manufacturing program leads to a $50 \%$ increase in carbon emissions as measured in ppmv.

The manufacturer must make some weighting choices between economics and the environment. Suppose in our example that the manufacturer selected a maximum impact of a $10 \%$ increase in carbon emissions in ppmv. Recall from the guide that maximum impact is the largest acceptable increase in environmental impact. Remember in the first scenario that our NPV was about $\$ 2.1$ million dollars. Because this project is generating a $50 \%$ increase in carbon emissions, by the manufacturer's own stated criteria the widget manufacturing project must be rejected. This decision can be depicted graphically as shown in Figure B-1. The environmental assessment results in a reject; so, the investment is rejected. 


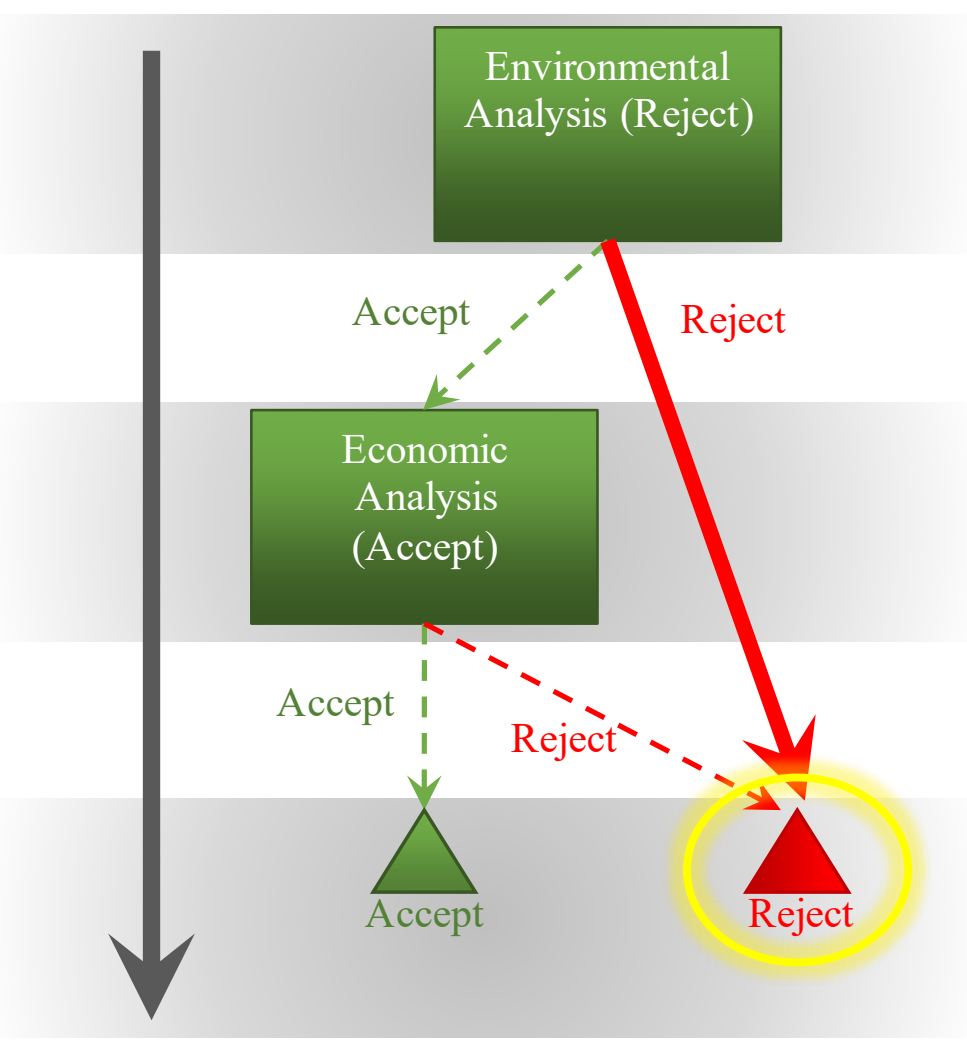

Figure B-1: Decision Tree for Example 3

Here, the manufacturer's criteria lead to a reject decision, which equates to Scenario 1.3 in Table 2.3 where the economic assessment is an accept but the environmental assessment results in rejecting the investment. Note that the standard does not dictate the weight given to environmental considerations against economic ones.

Example 4 (environmental hurdle rate and NPVP): Now suppose that the manufacturer decides on an environmental hurdle rate of $\$ 37500$. Recall that this represents the net present value of income or cost savings needed to compel a one percent increase (or, in some cases, one unit increase) in environmental impact. We will continue to use the NPV formula and the negative and positive cash flows throughout the life of the project seen in example 3 .

Remember in example 3 with variable yearly cash flows, the NPV was calculated to be $\$ 3.25$ million and our project is generating a $50 \%$ increase in ppmv. The net present value per percent change in environmental impact can be calculated as:

$$
N P V P=\frac{3248921}{50 \%}
$$


The NPVP is $\$ 64978$. Because the NPVP is above the hurdle rate of $\$ 37500$, she will accept the investment in the widget manufacturing program. The evaluation is illustrated in the decision tree in Figure B-2.

Example 5 (NPV, IRR, environmental hurdle rate, and NPVP): In place of using $\mathrm{NPV}$, a manufacturer might use the IRR for the economic analysis. Given the fact that IRR is more difficult to calculate than NPV, the manufacturer might decide to opt for an NPV calculation. The IRR has the benefit of telling the manufacturer the rate of return that is needed for a project to be accepted. Recall that Table A-2 illustrates the relationship between the IRR and NPV and the discount rate, $r$. Let us return to the example that we used to calculate the NPV, only with new numbers. But before we do that, let us define our environmental parameters anew. Suppose that our manufacturer decides that she will tolerate a one percent increase in ppmv per $\$ 20000$ in net present value; that is, an environmental hurdle rate of $\$ 20000$. An additional requirement for the manufacturer is that the IRR is at least $20 \%$.

Assume again that the project has a 5-year life cycle and that there was a cash flow for every year. Let us assume again that the initial outlay of cash was 2000000 . But this

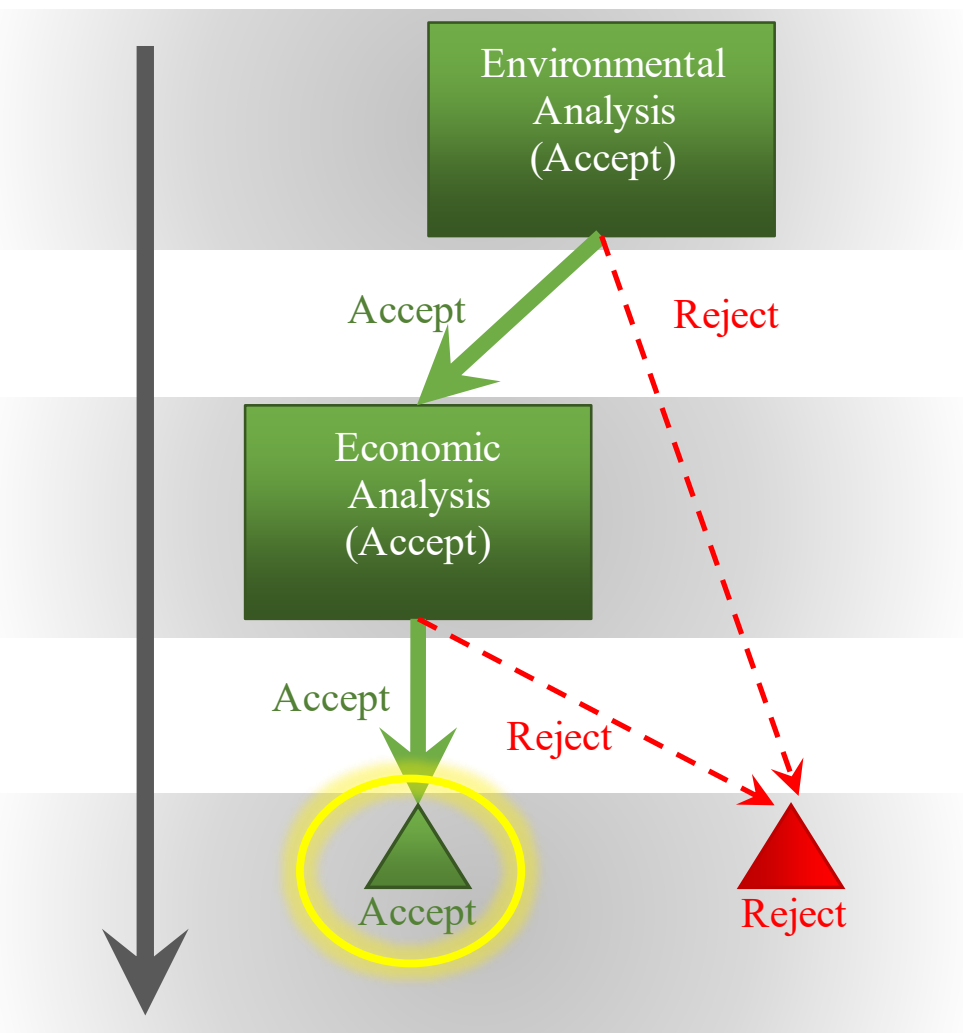

Figure B-2: Decision Tree for Example 4 
time we will assume new cash flows for each year for our manufacturer and her widget project (see Table B-2). The increase in environmental impact is $40 \%$.

Table B-2: Annual Cash Flows for Example 5

\begin{tabular}{|l|l|}
\hline Year 1 & 2000000 \\
\hline Year 2 & -3000000 \\
\hline Year 3 & -1000000 \\
\hline Year 4 & 4000000 \\
\hline Year 5 & 5000000 \\
\hline
\end{tabular}

Notice that some of the cash flows are negative. Using the numbers above, we can solve the NPV using the formula below:

$$
2000000
$$

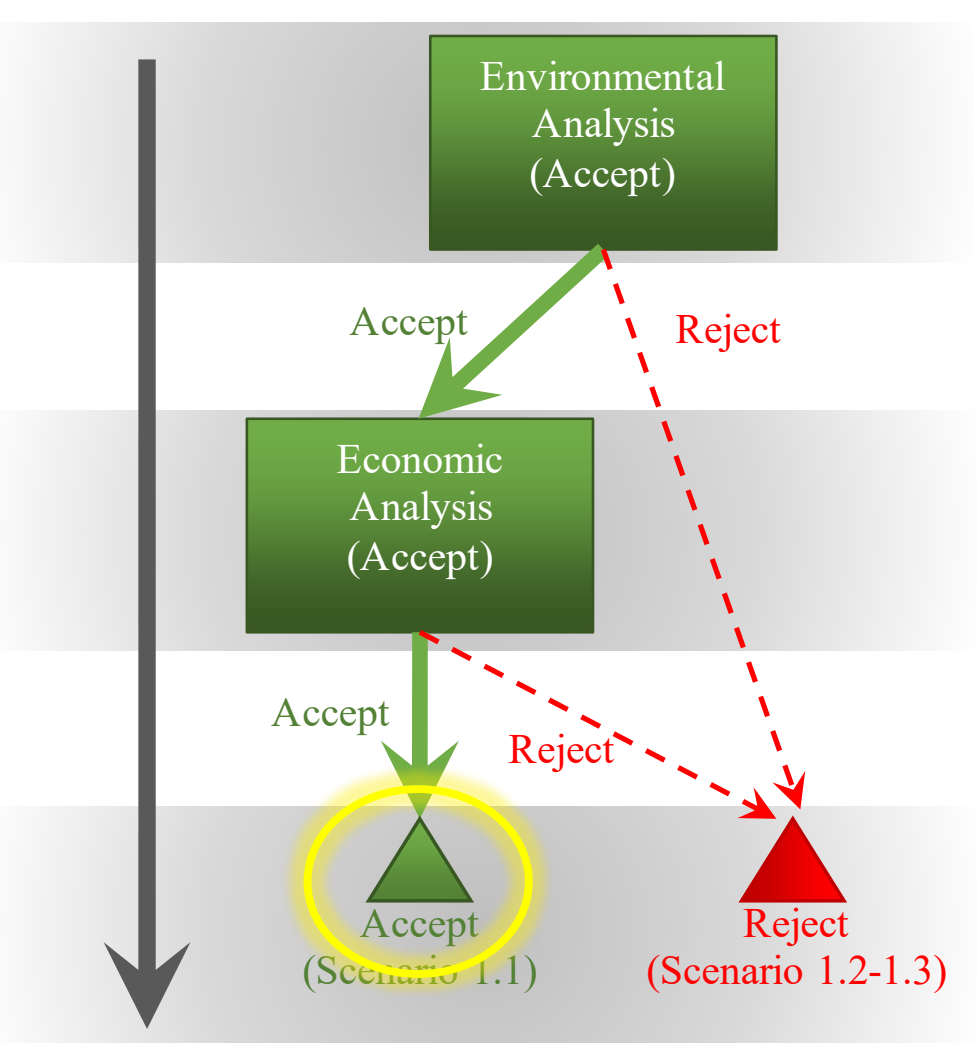

Figure B-3: Decision Tree for Example 5 
The NPV is approximately $\$ 3.8$ million. The IRR is estimated to be $30.82 \%$ by setting the NPV to zero and solving for $r$. That means that at a discount rate of $30.82 \%$, the present value of all cash flows equals the initial outlay. The NPVP is calculated as \$94 432 using the formula below:

$$
N P V P=\frac{\$ 3789264}{40 \%}
$$

Remember in our analysis that we were only looking for a value where the IRR is $20 \%$ and an NPVP of $\$ 20000$. Thus, we select the widget manufacturing operation, as it is accepted under the criteria, as illustrated in the decision tree in Figure B-3.

Example 6 (IRR): Let us use the five-year time horizon again and assume an initial outlay of 2000000 and a scenario where all of the cash flows are negative except in the final year of the manufacturing widget project (see

Table B-3). Let us keep the IRR threshold of $20 \%$. The IRR can be found by solving for $r$ in the equation below:

$$
0=\sum_{\mathrm{T}=1}^{5} \frac{-2000000}{(1+\mathrm{r})^{1}}+\frac{-3000000}{(1+\mathrm{r})^{2}}+\frac{-1000000}{(1+\mathrm{r})^{3}}+\frac{-4000000}{(1+\mathrm{r})^{4}}+\frac{5000000}{(1+\mathrm{r})^{5}}-2000000
$$

Solving for $\mathrm{r}$ yields

$$
\mathrm{IRR}=-30.92 \%
$$

Table B-3: Annual Cash Flows for Example 6

\begin{tabular}{|c|c|}
\hline Year 1 & -2000000 \\
\hline Year 2 & -3000000 \\
\hline Year 3 & -1000000 \\
\hline Year 4 & -4000000 \\
\hline Year 5 & 5000000 \\
\hline
\end{tabular}

Here with non-positive cash flows every year, except for the final year, we get a negative IRR, which indicates that the projected manufacturing line would probably not be pursued. By varying the cash flows, number of years of the project's life, and the initial cash outlay, the manufacturer can calculate several IRR's that allows her to know the rate of return required for each project. Although the tradeoff should have been determined, the environmental impact need not be calculated here because the manufacturer, in this instance, will not embark on a project with a negative cash flow.

Example 7 (payback period and maximum impact): Moving away from the formula that forms the basis of NPV and IRR, we can examine the concept of the payback period, the third formula showcased in this appendix. Recall that the payback period is the amount of time required to recover the costs associated with a project, as discussed in the Annex. This figure is always expressed as a time period, usually in number of years. 
To illustrate the Payback Period formula in action, let us assume a case where a manufacturer wants to know how long it will take her to recover the costs associated with her widget manufacturing project. Let us also stipulate that the manufacturer is willing to incur a maximum $35 \%$ increase in carbon and requires a discounted payback period of no more than 15 years.

Let us assume an initial investment amount of $\$ 2000000$, a discount rate of $4 \%$, and an annual cash inflow of $\$ 100000$ per year. The discounted payback period can be calculated as:

$$
D P P=\frac{\ln \left(\frac{1}{1-\left[\frac{2000000 * .04}{100000}\right]}\right)}{\ln (1+0.04)}
$$

Here, the calculation leads to a discounted payback period (DPP) of 41.04 years or rounding up, 42 years. Further assume we calculated the environmental impact to be $20 \%$. The environmental impact is below the maximum; however, the discounted payback period exceeds the threshold. Therefore, the investment is rejected, as illustrated in the decision tree in Figure B-4. Please note that this is the result in the somewhat artificial scenario where all the periodic cash flows (PCF) are uniform.

Example 8 (payback period and maximum impact): Say that our manufacturer faces a four-year time horizon, where the payback period cannot exceed 4 years, and that she has less funds on hand for the initial investment - say 1000000 . The environmental impact is a $20 \%$ increase in their current impact. Assume a discount rate of $3 \%$ throughout this period and cash flows of 500 000; $68000 ; 39000$; and 430000 during the four years. The manufacturer has a maximum impact of $35 \%$; that is, the impact cannot exceed $35 \%$. We can estimate a Payback period using Table B-4. The Payback Period is rounded to 4 years. Both the payback period and the environmental impact are below the threshold level criteria; therefore, the investment is accepted.

Example 9 (maximum impact, hurdle rate, and WACC): Payback Period formulas are often used for risk mitigation because they give a quick picture of the amount of time required to recover an investment. Focusing exclusively on Payback Period has its drawbacks as well because the manufacturer might be tempted to focus exclusively on the amount of time it takes to recover initial project funds and thus ignore potentially profitable projects that require longer time horizons to recover the initial project funds. The Payback Period formula, in its common forms, also assumes that the initial capital investment is a one-time event and that no further cash flows will be required in the future. It also does not take into account cash flows outside of the relevant time frame. 


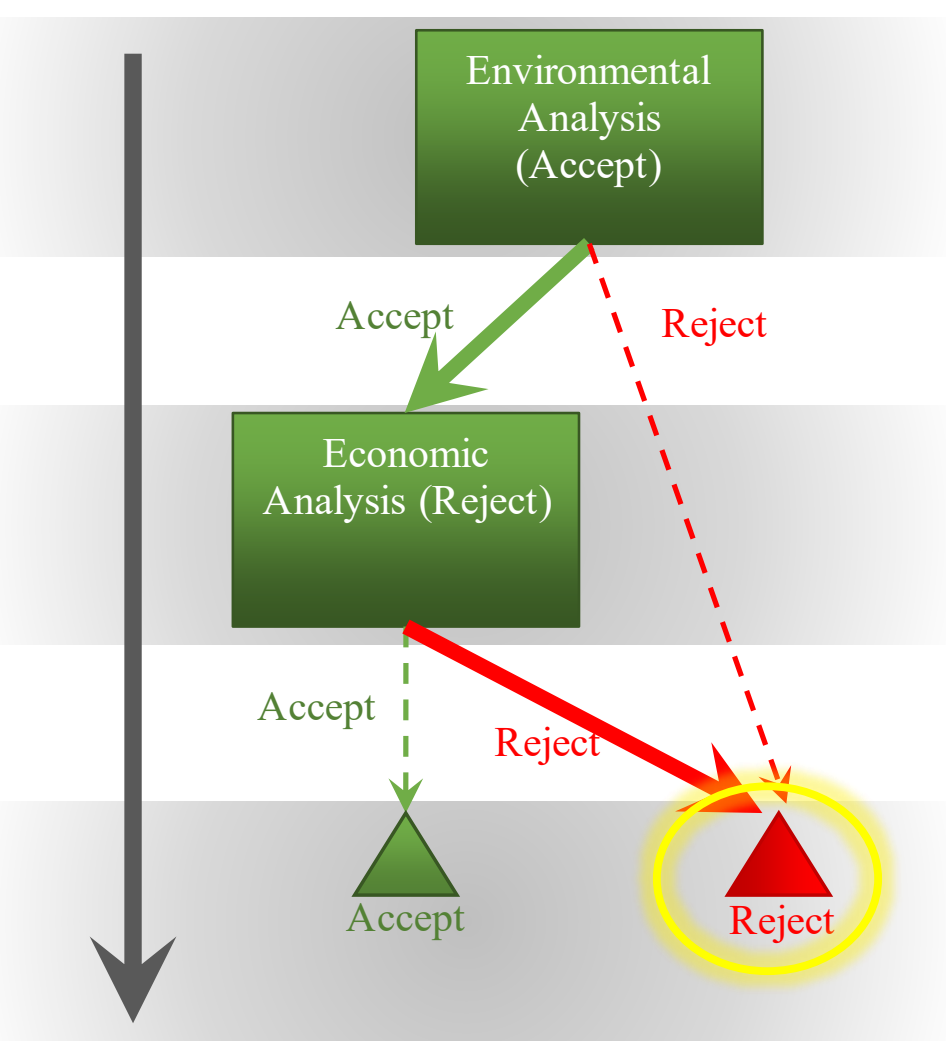

Figure B-4: Decision Tree for Example 7

Table B-4: Annual Cash Flows for Example 8

\begin{tabular}{|l|l|l|l|l|}
\hline & Cash Flow & Net Cash Flow & $\begin{array}{l}\text { Discounted Cash } \\
\text { Flow }\end{array}$ & $\begin{array}{l}\text { Net Discounted Cash } \\
\text { Flow }\end{array}$ \\
\hline Year 0 & $\$-1000000.00$ & $\$-1000000.00$ & $\$-1000000.00$ & $\$-1000000.00$ \\
\hline Year 1 & $\$ 500000.00$ & $\$-500000.00$ & $\$ 485436.89$ & $\$-514563.11$ \\
\hline Year 2 & $\$ 68000.00$ & $\$-432000.00$ & $\$ 64096.52$ & $\$-450466.58$ \\
\hline Year 3 & $\$ 39000.00$ & $\$-393000.00$ & $\$ 35690.52$ & $\$-414776.06$ \\
\hline Year 4 & $\$ 430000.00$ & $\$ 37000.00$ & $\$ 382049.43$ & $\$-32726.63$ \\
\hline
\end{tabular}

Another financial formula that the manufacturer should be aware of is the hurdle rate. The hurdle rate is the bare minimum rate of return required by the manufacturer to initiate a project. While the manufacturer has several different methods of calculat ing the hurdle rate, we will focus on one technique that is commonly used and has the added 
benefit of being robust. That formula is the weighted average cost of capital, or WACC, presented in equation 10 .

Notice that unlike previous formulas discussed in this appendix, the WACC formula which we use to calculate the hurdle rate looks at the market value of the firm's equity and debt and incorporates calculations of the tax rate. To properly calculate the WACC, the manufacturer must have a sophisticated understanding of the nature of her firm and know the ways in which it is financed, as well as the effective tax rate face by her firm. Some firms might have no equity (which might be the case if the manufacturing firm is a partnership or a sole proprietorship).

So, let us now stipulate that our manufacturer uses the WACC as a hurdle rate and requires a carbon increase of no more than $35 \%$ (i.e., a maximum impact of $35 \%$ ). The investment has the same cash flows and discount rate as those in example 8.

For our example, let us assume that the manufacturer faces an effective tax rate of $20 \%$, a cost of equity of $9 \%$, a cost of debt of $14 \%$, total debt of 500000 , and total equity of 300000 . Using the formula above, we can then calculate our hurdle rate to be:

$$
\begin{gathered}
W A C C=\frac{300000}{800000} * .09+\frac{500000}{800000} * .14 *(1-.20)= \\
9.75 \%
\end{gathered}
$$

In this example then the effective hurdle rate is $9.75 \%$ to embark on this manufacturing project. The IRR is estimated to be $1.55 \%$. Assume the carbon output of the project is now $17 \%$. The environmental analysis results in an accept, as the impact is less than the threshold; however, the IRR is less than the hurdle rate. Therefore, the economic analysis results in a reject and the investment is rejected, as illustrated in Figure B-5.

The WACC formula is easy to understand but in practice it might be more difficult to use as the precise mixture of debt and equity in a firm might be complex and ever-changing. However, the challenges presented by the formula also contribute to making it a valuable tool for the manufacturer decision-maker.

\section{Example 10 (multiple investment alternatives, MEER, NPV, IRR, and pairwise} comparison): Let's consider an example with multiple investment alternatives. We will use a 10-year study period, a $4 \%$ discount rate, a \$2 000 environmental hurdle rate, and a $\$ 2000$ maximum environmental expenditure rate (MEER). The status quo (i.e., the base case) in this example requires $\$ 25000$ in machinery repairs.

Alternative 1 includes the purchase of a new piece of machinery, which is $\$ 100000$ and would decrease annual maintenance costs by $\$ 8000$. At the end of the study period, the machinery would have a positive $\$ 10000$ salvage value. Environmental impact would be decreased by $5 \%$. 


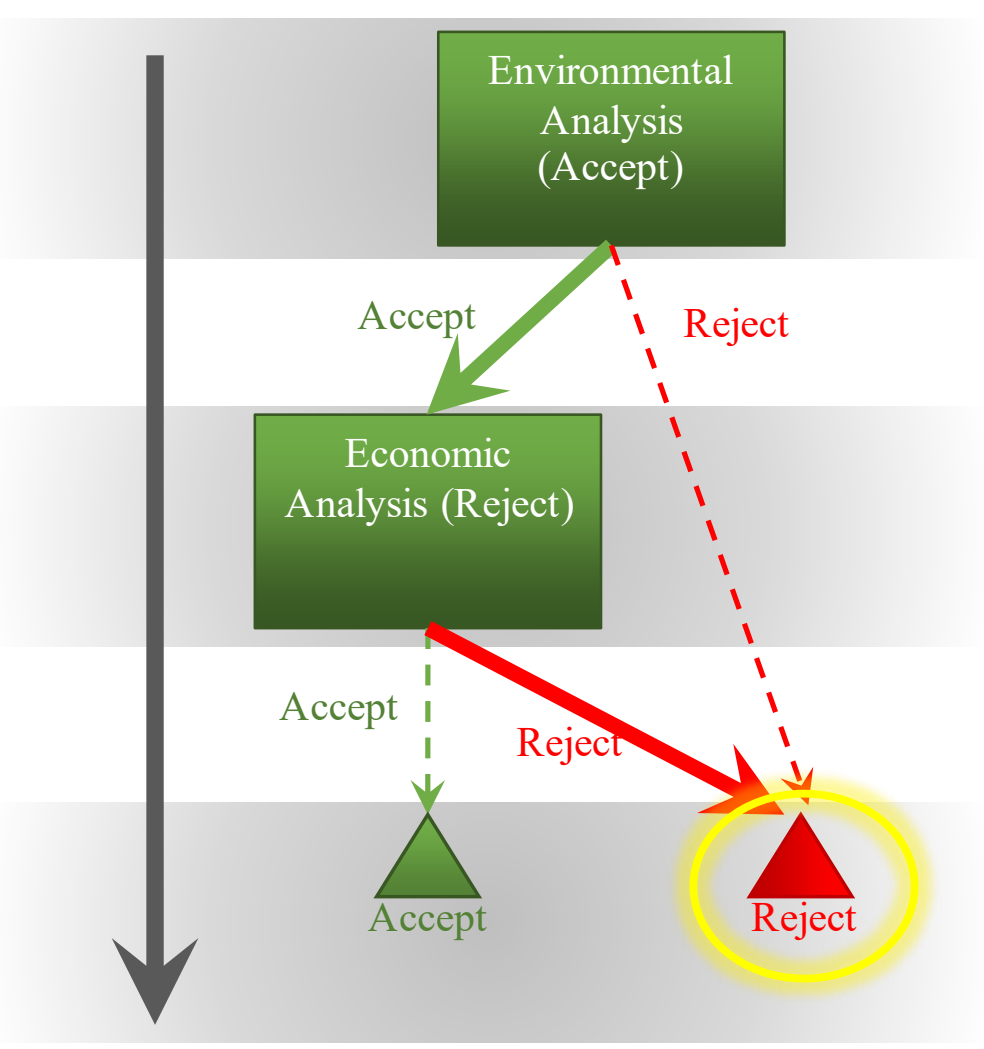

Figure B-5: Decision Tree for Example 9

\begin{abstract}
Alternative 2 also includes the purchase of a new piece of machinery. The cost is $\$ 150$ 000 and it reduces annual maintenance costs by $\$ 20000$ while reducing environmental impact by $10 \%$. This piece of machinery would have a $\$ 20000$ salvage value.
\end{abstract}

Alternative 3 is to purchase a high-efficiency piece of machinery. This requires a $\$ 200$ 000 initial investment but reduces maintenance costs by $\$ 20000$ and energy costs by $\$ 4$ 000 annually. It also decreases environmental impact by $20 \%$ and has a $\$ 30000$ salvage value.

Table B-5 shows the NPV, IRR, and environmental impact for the 4 options. We can work through the comparison of each option (i.e., base case and alternatives) to each of the other options using the decision tree in Figure 7. Table B-6 shows the outcomes. The NPV, IRR, and environmental impact indicate that alternative 2 and alternative 3 are preferred when compared to the base case. That is, the NPV and IRR are higher for both alternatives and the environmental impact is more favorable. Alternative 1 has a tradeoff where it is not financially economical, but it is environmentally favorable when compared to the base case; therefore, there is a question mark in Table B-6 where the base case and alternative 1 are compared. We do not need to formally compare alternative 1 to alternative 2 or to alternative 3 , because we can see that alternative 2 and alternative 3 have a higher NPV, IRR, and the environmental impact is more favorable. 
Thus, in this instance, we can reject alternative 1, as we are only choosing one alternative and do not need to know if the base case or alternative 1 rank higher. If we needed to know how alternative 1 ranked compared to the base case, a pairwise comparison would be needed.

We have rejected the base case and alternative 1; however, we do not know the rank of alternative 2 compared to alternative 3 , which is indicated with a question mark in Table B-6. Choosing between alternative 2 and alternative 3 requires a pairwise comparison, as there is a tradeoff between the two. Alternative 2 has a higher NPV and IRR, but it is a less favorable environmental impact. To conduct a pairwise comparison we can make alternative 2 our new base case.

Table B-5: Environmental and Economic Assessment

Base Case

(status Alternative1 Alternative2 Alternative3 quo)

\begin{tabular}{lcccc}
\hline Net Present Value (\$) & - & -3357 & 50729 & 39928 \\
Internal Rate of Return & - & $3.2 \%$ & $11.0 \%$ & $8.0 \%$ \\
Environmental Impact & - & $-5.0 \%$ & $-10.0 \%$ & $-20.0 \%$ \\
\hline
\end{tabular}

Table B-6: Pairwise Comparisons

\begin{tabular}{lcccc} 
& Base Case & Alternative 1 & Alternative 2 & Alternative 3 \\
\cline { 2 - 5 } Base Case & ? & Alt. 2 is preferred & Alt. 3 is preferred \\
Alternative 1 & & & Alt. 2 is preferred & Alt. 3 is preferred \\
Alternative 2 & & & & ? \\
Alternative 3 & & & &
\end{tabular}

Pairwise comparison: For a pairwise comparison, the environmental impact for alternative 3 is calculated by utilizing equation 1 . Note that equation 1 equates to subtracting the percent change of one alternative from another. This can be shown as:

$$
\frac{\left(E I_{b}-E I_{a}\right)}{E I_{a}{ }^{\prime}} * 100=\left(\frac{E I_{b}}{E I_{a}{ }^{\prime}} * 100\right)-\left(\frac{E I_{a}}{E I_{a}{ }^{\prime}} * 100\right)
$$

The results of the pairwise comparison are shown in Table B-7. Note that alternative 2 is our new base case and the NPV, IRR, environmental impact, and NPVP for alternative 3 are calculated in comparison to alternative 2. Alternative 3 is not financially economical relative to alternative 2 , as the net present value is negative and there is no rate of return (i.e., it is negative). However, alternative 3 is environmentally favorable. The NPVP shows that the tradeoff is $\$ 1080$ per percent decrease in environmental impact, which is less than the MEER; therefore, the trad eoff analysis ranks alternative 3 above alternative 
2 , making it the highest ranked, given the manufacturer's preferences. In this instance, the manufacturer is willing to spend money to reduce their environmental impact and the expenditure is below their maximum price (i.e., the MEER).

Table B-7: Pairwise Comparison

\begin{tabular}{lcc} 
& $\begin{array}{c}\text { Base Case } \\
\text { (Alternative 2) }\end{array}$ & Alternative 3 \\
\hline Net Present Value (\$) & - & -10801 \\
Internal Rate of Return & - & - \\
Environmental Impact & - & -10 Percentage Points \\
Net Present Value per & & 1080 \\
Percent Increase in & - & \\
Environmental Impact (\$) & & \\
\hline
\end{tabular}

Summary: In conclusion, the financial formulas and the environmental formula above will aid the manufacturer as she tries to determine the benefits of embarking on a new project. But no formula can substitute for the judgment required by the manufacturer in making the tradeoff between economic and environmental concerns. That determination will require value judgments whose ultimate authority resides in the decision-maker. 